Article

\title{
Tyre curve estimation in slip-controlled braking
}

Jonathan I Miller and David Cebon

Cambridge University Engineering Department, Cambridge, UK

First submitted November 2013

Accepted for publication 28 Jan 2015

Final revision March 2015

Corresponding author:

David Cebon, Cambridge University Engineering Department, Trumpington Street, Cambridge, CB2 1PZ, UK.

Tel: +4401223 332665

Fax: +44 01223332662

Email: dc@eng.cam.ac.uk 


\title{
Tyre curve estimation in slip-controlled braking
}

\begin{abstract}
Progress in reducing actuator delays in pneumatic brake systems is opening the door for advanced anti-lock braking algorithms to be used on heavy goods vehicles. However, these algorithms require knowledge of variables that are impractical to measure directly. This paper introduces a braking force observer and road surface identification algorithms to support a sliding mode slip controller for air-braked heavy vehicles. Both the force observer and slip controller are shown to operate robustly under a variety of conditions in quartercar simulations. A nonlinear least squares algorithm was found to be capable of regressing all parameters of the UMTRI tyre model when used 'in-the-loop' with the controller and the observer. A recursive least squares algorithm that is less computationally expensive than the nonlinear algorithm was also investigated, but only gave reasonable estimates of the UMTRI model parameters on high friction, smooth roads.
\end{abstract}

\section{Keywords}

Emergency braking, pneumatic actuators, force observer, surface identification, sliding mode, least squares

Submitted November 2013

\section{Introduction}

Commercial road vehicles are a vital part of the economy, moving seven times more

freight in the UK in tonne kilometres than trains ${ }^{1}$. However, Heavy Goods

Vehicles (HGV) require 40\% more distance for braking than passenger cars on dry roads, contributing to their higher rate of involvement in fatal accidents than other vehicles. $^{2-4}$ The mandatory use of anti-lock braking systems (ABS) on articulated vehicles in North America and Europe has helped improve heavy vehicle braking performance somewhat. However, current HGV ABS systems use inefficient, heuristic control approaches that work on cycles of predicting and superseding the limits of tyre-road adhesion, and then reducing the brake pressure to allow the wheel to rotate again. 5 
Part of the reason for the heuristic control approach to HGV ABS is the notoriously slow pneumatic actuators in their braking systems. This results in HGV ABS systems cycling at frequencies of $1-2 \mathrm{~Hz}$, with the periodic locking and unlocking of the wheel substantially reducing the braking force (by comparison, passenger car ABS cycles at frequencies of 6-8 Hz). ${ }^{6,7}$ It has been shown in Miller et al. ${ }^{8,9}$ that actuation delays in heavy vehicles could be reduced by an order of magnitude (from over $40 \mathrm{~ms}$ to under $4 \mathrm{~ms}$ ) by placing fast pneumatic valves featuring "binary-actuation" technology directly on brake chambers, instead of conventional valves located on a central controller (ECU). Such reductions in actuation delay and mechanical hysteresis would allow advanced braking control methods, such as slip control, to be used on pneumatically braked vehicles. Slip control seeks to optimise wheel slip continuously during braking, thereby maximizing deceleration while maintaining vehicle maneuverability. Preliminary estimations with a proof-of-concept control system and vehicle simulation predict reductions of up to $35 \%$ in braking distance relative to conventional $\mathrm{ABS}^{8}$

In general, however, slip controllers tend to use the braking force between the tyre and the road as a control variable, and the vehicle speed must be known to evaluate the slip. In addition, knowledge of the slip-friction characteristics of the tyreroad system is typically needed, so that the maximum-braking point on the slipfriction curve can be identified and used as a controller set point. It is not practical to measure these variables directly, so they must be estimated.

In this paper, a sliding mode slip controller is presented, along with the braking force estimation and road surface identification algorithms required to support the controller. Speed estimation is also an important topic. However, presenting an appropriate algorithm in adequate detail would require a lengthy discussion that is 
considered out of the scope of this paper. Instead, examples of speed estimation algorithms can be found in [10-13].

The architecture of the combined control system that will be presented in this paper is shown in the block diagram of Figure 1. The tasks of estimating the braking force and the wheel slip curve are separated, to eliminate the need for a priori knowledge of a braking force model. The paper begins with a literature review, following which a braking simulation as well as the slip controller are introduced. A braking force observer and slip curve regression strategies are then presented. Slip curve regression is investigated in both the fully nonlinear, multi-variable cases, and in the more easily implemented recursive case, with the aim of identifying the maximum-braking point on the slip curve.

\section{Literature review}

\section{Braking force estimation}

Several approaches have been taken towards tyre friction force estimation in the literature. Ray ${ }^{14}$ used a nonlinear Extended Kalman Filter (EKF) based on an 8 degree of freedom car model to estimate the tyre forces in the longitudinal and lateral directions. Extended Kalman filters with the states augmented by the unknown forces were also used by Shim et al. ${ }^{15}$, and Hong et al. ${ }^{16}$

Unsal and $\mathrm{Kachroo}^{17}$ compared an EKF with a sliding mode observer to estimate vehicle velocity, using this estimated velocity with a nominal slip-friction curve to determine the braking force. The authors preferred the sliding observer because it was robust against errors in the assumed road friction.

Drakunov et al. ${ }^{18}$ used a simple sliding mode observer to estimate only the longitudinal braking force of a vehicle. Similar observers were applied by Choi et 
al., ${ }^{19}$ and by Ribbens et al., ${ }^{20,21}$ but it was shown by Miller and Cebon ${ }^{22}$ that these observers would be susceptible to parametric errors such as brake gain variations. Tyre forces in both the lateral and longitudinal directions were estimated with a sliding mode observer by Cadiou et al. ${ }^{23}$ The estimator produced plausible force time histories, but the results showed significant scatter when plotted on slip-friction curves.

\section{Tyre curve identification}

Knowledge of the road friction level and the shape of the slip-friction curve allows the maximum-braking point to be identified. Sensors exist for identifying different surface types,${ }^{24}$ but these sensors provide limited information about the necessary friction parameters, and tend to be impractical to use on ordinary road vehicles. ${ }^{25}$

Estimating the entire slip-friction curve. $\quad$ Ray $^{14}$ decoupled friction estimation from tyre force estimation, allowing the vehicle states to be available for control immediately, and the tyre curve to be available for controller set points once it had been identified by a Baysian hypothesis selection algorithm. Rather than separating parameter and state estimation, Hodgson and Best $^{26}$ used an adaptive identifying Kalman Filter (IKF) to estimate some of the parameters of the "magic formula" tyre model together with the vehicle dynamics states, and showed that an IKF would outperform an EKF when the vehicle's tyres saturated.

A nonlinear observer based on a Lyapunov approach was used by Yi et al. ${ }^{27}$ on a quarter-car vehicle to determine the friction internal state of a LuGre tyre model and the Coulomb friction of the road surface. Alvarez et al. ${ }^{28}$ extended this analysis by adding the longitudinal acceleration as a measured variable, arguing that this enhanced system observability. 
The adaptive observer presented by Yi et al. ${ }^{27}$ was compared to second order and third order, fixed-gain sliding mode observers based on quarter car dynamics by Patel et al. ${ }^{29,30}$. The adaptive observer gave the least accurate results on higher friction roads in simulations, but it is unclear to what extent the adaptive observer was tuned in relation to the sliding mode observers under those conditions.

Identifying different parts of the tyre curve. Tyre models in the literature tend to assume that the linear relationship between force and slip at low slips remains the same regardless of the surface being driven on. Contrary to this, Gustafsson ${ }^{25}$ exploited the differences in tyre stiffness on different roads for surface identification by estimating the 'slip slope' at low slips with a Kalman filter. The approach was only suitable for normal driving, and required special calibration to estimate the absolute friction. Yi et al. ${ }^{31}$ similarly used a "reduced order observer/filtered regressor-based identifier" with vehicle test data to differentiate between dry and wet roads, based on a nonlinear mapping of the slip slope at low slips for different surfaces.

Pasterkamp and Pacejka ${ }^{32}$ relied on neural networks to learn relations between several variables of the brush tyre model to estimate the road friction and side-slip angle. In contrast to Gustafsson, they observed a degradation in the quality of estimates of the road friction in simulations and vehicle tests for low slips and high friction values, because the tyre behaviour was independent of the road friction.

Many algorithms presented in the literature focus on estimating only a subset of the total number of parameters needed to describe the tyre curve. Furthermore, the force estimation algorithms are predominantly presented for cars, whose tyre characteristics and dynamic behaviour differ significantly from those for trucks. ${ }^{33}$ The 
work in this paper will present a sliding mode controller and force observer tuned for HGVs, as well as an algorithm to estimate the entire slip-curve.

\section{Braking simulation}

\section{Vehicle and road}

A modified version of the validated 'quarter-car' braking simulation presented by

Kienhofer et al. ${ }^{5}$ was used for control system design (see Figures 1 and 2), and will be introduced in this section. The model had four degrees of freedom: longitudinal motion of the vehicle, rotational motion of the wheel, and vertical motion of the sprung and unsprung masses. The longitudinal motion of the vehicle and the rotational motion of the wheel were described by,

$$
\begin{aligned}
& F_{x}+m_{V} \dot{v}_{x}=0 \\
& J_{w} \dot{\omega}_{w}-r_{b} F_{x}+T_{B}=0
\end{aligned}
$$

where $F_{x}$ is the longitudinal tyre force (braking force), which is derived from a tyre model that will be described shortly, $m_{V}$ is the total vehicle mass, $v_{x}$ is the longitudinal velocity of the vehicle, $\omega_{w}$ is the rotational speed of the wheel, $T_{B}$ is the braking torque, $r_{b}$ is the radius through which the braking force acts, which is not necessarily equal to the rolling radius, ${ }^{34}$ and $J_{w}$ is the polar moment of inertia of the wheel.

It was assumed that: braking torque is proportional to the pressure in the brake chamber, $P_{c}$; disc brakes are used; there is one brake pad on either side of the disc; and that the emergency stop is short enough that brake fade could be neglected. ${ }^{33,35}$ Hence,

$$
T_{B}=2 A_{c} q_{c} \mu_{b r} r_{b r} P_{c}
$$


where $A_{c}$ is the effective force-area of the chamber diaphragm, $q_{c}$ is the lever ratio in the calliper, $\mu_{b r}$ is the coefficient of friction between the brake disc and pads, and $r_{b r}$ is the effective radius of the brake pads on the disc. The combination of $2 A_{c} q_{c} \mu_{b r} r_{b r}$ is called the 'brake gain,' $G$.

Brake chamber charging and discharging dynamics were described using onedimensional flow theory and the thermodynamic relations for unsteady flow through an open system, as presented by Miller and Cebon. ${ }^{9}$ It was assumed that pulse-width modulated valves were used to control flow into and out of the chamber via a linear pressure controller, which is also detailed in Miller and Cebon. ${ }^{9}$

The vertical dynamics of the vehicle were described by ${ }^{36}$

$$
\left[\begin{array}{cc}
m_{S} & 0 \\
0 & m_{U}
\end{array}\right]\left[\begin{array}{c}
\ddot{z}_{S} \\
\ddot{z}_{U}
\end{array}\right]+\left[\begin{array}{cc}
c_{S} & -c_{S} \\
-c_{S} & c_{S}+c_{t}
\end{array}\right]\left[\begin{array}{c}
\dot{z}_{S} \\
\dot{z}_{U}
\end{array}\right]+\left[\begin{array}{cc}
k_{S} & -k_{S} \\
-k_{S} & k_{S}+k_{t}
\end{array}\right]\left[\begin{array}{c}
z_{S} \\
z_{U}
\end{array}\right]=\left[\begin{array}{c}
0 \\
c_{t} \dot{z}_{r}+k_{t} z_{r}
\end{array}\right]
$$

where $m, c$, and $k$ denote mass, damping, and stiffness respectively; $z$ is displacement, and the subscripts ' $t$ ', ' $r$ ', ' $U$ ', and ' $S$ ' denote the tyre, road, unsprung, and sprung masses respectively. The vehicle model was subjected to road surface roughness with specified spectral content corresponding to the ISO classification 8608:1995, ${ }^{37}$ and quantified by the International Road Roughness Index (IRI). ${ }^{38}$ Values used for the vehicle parameters in the simulations are shown in Table 1 . The values represent one wheel station on the trailer of an existing test vehicle ${ }^{39,40}$ when lightly loaded. This test trailer features experimental equipment on its axles, and so the unsprung mass may be slightly higher than for an ordinary trailer.

\section{Tyre forces}

Truck tyres have unusually high ratios of peak to slide friction when compared to other motor vehicles, and the broad range of loads covered by the heavy truck tyre 
causes large variations in the absolute peak and slide friction values. ${ }^{33}$ The semiempirical tyre model from the University of Michigan Transportation Research Institute (UMTRI) was used here to estimate braking forces. ${ }^{41}$ The model was used because it was derived based on data from full scale tests with truck tyres; it requires only four parameters to describe the entire slip-friction curve; and because it represents a wide variety of truck tyres accurately.

Wheel slip, $\lambda$, is defined in the UMTRI tyre model as:

$$
\lambda=\frac{v_{x}-r_{r} \omega_{w}}{v_{x}}
$$

where $r_{r}$ is the rolling radius of the wheel. Braking force is generated in the model by

$$
F_{x}=\frac{\left(\mu F_{z}\right)^{2}(1-\lambda)}{4 C_{0} \lambda}+\mu F_{z}\left(1-L_{x}\right)
$$

where $F_{z}$ is the vertical load on the tyre, $C_{o}$ is the longitudinal tyre stiffness, $L_{x}$ is the fraction of the contact patch that is not sliding, and $\mu$ is the friction coefficient, which varies with speed according to

$$
\mu=\mu_{f}+\left(\mu_{0}-\mu_{f}\right) e^{-\frac{v_{x}-\omega_{w} r_{r}}{V_{f}}}
$$

where $\mu_{o}, \mu_{f}$, and $V_{f}$ are factors describing the peak friction, slide friction, and the shape at the peak of the slip curve respectively. The longitudinal tyre stiffness varies with normal load according to:

$$
C_{o}=C_{1} F_{z}-\frac{F_{z}^{2}}{C_{2}}
$$


where $C_{1}$ and $C_{2}$ are constant coefficients that were set based on representative values given in Fancher. ${ }^{41}$ The fraction of the contact patch that is not sliding is given in the model by

$$
L_{x}=\frac{\mu F_{z}(1-\lambda)}{2 C_{o} \lambda}
$$

and is constrained to a maximum value of 1 . When $L_{x}=1$, at very low values of slip, there is no sliding in the contact patch. In this case, equation (6) can be rearranged as

$$
F_{x}=\frac{C_{0} \lambda}{(1-\lambda)}
$$

It can be seen in equation (7) that $\mu$ is related to the vehicle speed (see Figure 3 a)). As a result, the maximum tyre force occurs at an intermediate value of slip that rises towards 1 as the vehicle slows (see Figure $3 \mathrm{~b}$ )). The vertical force also affects the braking force. An increase in vertical force serves to increase the available braking force, but also to make the tyre longitudinally stiffer, as illustrated in Figure $3 \mathrm{c}$ ).

\section{Slip controller}

A variable structure, sliding mode approach was taken here for the slip controller in the braking simulation. Sliding mode controllers, being inherently nonlinear in nature, are particularly good for unstable plants with 'strong' nonlinearities, such as the wheel slip curve, ${ }^{42}$ and are more systematic to tune than traditional rule-based controllers. The full derivation of the controller, based on equations (2), (3), and (5), can be found in Miller et al., ${ }^{8}$ and a discussion about its robustness can be found in Miller. ${ }^{40}$ 
Both discussions are omitted here for brevity. The expression for the final controller is:

$$
P_{c}=\frac{r_{r} r_{b} F_{x}-(1-\lambda) \dot{v}_{x} J_{w}}{G r_{r}}-k_{s}\left\{\frac{s_{s}}{\left|s_{s}\right|+\delta_{s}}\right\}-\Phi_{s} s_{s}
$$

where $\Phi_{s}$ is a positive design constant, $\delta_{s}$, is the boundary layer width, $s_{s}=\lambda-\lambda_{d}, \lambda_{d}$ is the desired slip, and $k_{s}$ is the sliding gain.

A preliminary demonstration of the performance of the sliding mode wheel slip controller described by equation (11) will be given in this section. It was assumed in the first instance that the wheel speed, vehicle speed, braking force, and vehicle acceleration could be measured. The controller gains $k_{s}, \delta_{s}$, and $\Phi_{s}$ were iteratively tuned by simulating multiple stops with different gains, and plotting the resultant stopping distance and air (energy) usage from each stop on 'conflict plots.' The gains that provided the best tradeoff between stopping the vehicle in the shortest distance and minimizing the air used during fill and dump cycles were chosen from the plots. The complete details of the tuning and tradeoffs are the subject of another work by the authors, ${ }^{8}$ and are omitted here for brevity.

Figure 4 shows slip time histories of vehicle stops with sliding mode control on a perfectly smooth $(\mathrm{IRI}=0 \mathrm{~m} / \mathrm{km})$, high friction surface $\left(\mu_{o}=0.9\right.$, equivalent to dry asphalt). The parameters for the tyre curve were set based on representative values given in Fancher, ${ }^{41}$ which were derived from full-scale tests with truck tyres. The optimal slip point on this road is around 0.2 at the initial speed of $80 \mathrm{~km} / \mathrm{h}$, rising to 0.4 as the vehicle slows, due to the velocity dependence of the tyre curves in the UMTRI model (equation 7). The pneumatic valves in the brake actuator were assumed to have two $9 \mathrm{~mm}$ orifices (one at the inlet and one at the outlet) with 
actuation delays of $1 \mathrm{~ms}$. In Figure 4, three slip set points were used: 0.3, 0.6, and 0.9. Since velocity appears in the denominator of equation (5), slip measurements diverge as the vehicle comes to a rest. Consequently, keeping in line with industry practice, the brakes were fully engaged (the pressure was set to a constant 6.5 bar) in the simulation once the vehicle speed dropped below $2 \mathrm{~m} / \mathrm{s}$, driving the slip to 1 .

Figure 4 illustrates that the slip controller is able to follow demand slips deep into the unstable region of the slip curve. Moreover, as the target slip point was raised, the deceleration of the vehicle reduced. This is due to the reduction of tyre force with increasing slip levels beyond the peak of the slip curve, as shown in Figure 3.

Time histories for simulated stops on low friction $\left(\mu_{o}=0.2\right.$, equivalent to ice), medium friction $\left(\mu_{o}=0.4\right.$, equivalent to wet asphalt), and high friction $\left(\mu_{o}=0.9\right)$ surfaces are shown in Figure 5. This time, the slip set points were set to the optimal slip value for each surface, which is dependent on speed. It can be seen that the controller is also robust to different levels of surface friction.

\section{Sliding mode force observer}

In the previous section, it was assumed that braking force could be measured. In this section, a braking force observer will be derived and demonstrated to support the sliding mode controller, as shown in Figure 1. Past studies on parameter and state estimation in emergency braking have predominantly focussed on cars. However, heavy vehicles have very different tyre characteristics and dynamic behaviour to cars ${ }^{33}$ and so represent a significantly different estimation problem.

\section{Observer equations}

A sliding mode observer was chosen here to estimate the tyre tractive forces because, unlike Kalman filters, sliding mode observers have stability guarantees. ${ }^{42,43}$ 
Moreover, the observers can handle strongly nonlinear systems and are robust to model mismatches. ${ }^{42,44}$ In standard state space notation, the governing equations for the sliding mode observer can be written as

$$
\begin{aligned}
& \hat{\mathbf{x}}=\mathbf{A} \hat{\mathbf{x}}+\mathbf{B} u+\mathbf{L}(\mathbf{y}-\hat{\mathbf{y}})+\mathbf{k}_{\mathrm{o}} \operatorname{sgn}(\mathbf{y}-\hat{\mathbf{y}}) \\
& \boldsymbol{y}=\mathbf{C} \boldsymbol{x}
\end{aligned}
$$

where $\mathbf{L}$ and $\mathbf{k}_{\mathbf{o}}$ are design gains, and '^’ denotes an estimate. Equations (12) and (13) show that the sliding observer consists of a Luenberger observer with an appended switching term, which provides robustness by accounting for such non-idealities as modelling errors. ${ }^{42,44}$

The shape of tyre slip-friction curves can change drastically on different surfaces and as the tyres wear (this will be illustrated further in the section "Optimal slip point estimation.") Consequently, it was decided to follow the method of Ray ${ }^{14}$ (which was not based on a sliding mode observer) and treat the tyre force as an unknown parameter to be estimated, rather than assuming a tyre model in advance. The longitudinal force was described using a random walk model, ${ }^{14,45}$ whereby random white noise was appended to the tyre force and its first derivative. It was assumed that the wheel speed, longitudinal acceleration, and brake chamber pressure could be measured, and that the vehicle mass was known (eg. from onboard weighing systems, which are commonly fitted to heavy vehicles). Based on these assumptions, and combining equations (1)-(3) into (12) and (13), the state equations for the system are 


$$
\begin{aligned}
& \dot{\boldsymbol{x}}=\left[\begin{array}{c}
\dot{\omega}_{w} \\
\dot{F}_{x} \\
\ddot{F}_{x}
\end{array}\right]=\left[\begin{array}{ccc}
0 & \frac{r_{b}}{J_{w}} & 0 \\
0 & 0 & 1 \\
0 & 0 & 0
\end{array}\right]\left[\begin{array}{c}
\omega_{w} \\
F_{x} \\
\dot{F}_{x}
\end{array}\right]+\left[\begin{array}{c}
-\frac{2 A_{c} q_{c} \mu_{b r} r_{b r}}{J_{w}} \\
0 \\
0
\end{array}\right] P_{c}+\boldsymbol{w}_{s} \\
& \boldsymbol{y}=\left[\begin{array}{c}
\dot{v}_{x} \\
\omega_{w}
\end{array}\right]=\left[\begin{array}{ccc}
0 & -\frac{1}{m_{V}} & 0 \\
1 & 0 & 0
\end{array}\right]\left[\begin{array}{c}
\omega_{w} \\
F_{x} \\
\dot{F}_{x}
\end{array}\right]+\boldsymbol{w}_{m}
\end{aligned}
$$

where $\boldsymbol{w}_{\boldsymbol{s}}$ and $\boldsymbol{w}_{\boldsymbol{m}}$ represent vectors of random noise in the states and measurements respectively. From equations (14) and (15), it can be shown that a system with a single wheel is observable without the acceleration as an output, since the system's observability matrix is of full rank. However, accelerometers are commonly available in commercial emergency braking systems, so it was of interest to explore whether the extra information from this sensor would improve the efficacy of the observer.

\section{Observer results}

The simulations in the section "Slip controller" were intended to illustrate the performance of the sliding mode controller under noise-free conditions, when all states and parameters are known. To evaluate the influence of sensor noise, bandlimited white noise with a sample time of $0.002 \mathrm{~s}$ (the cycling period of the voltage input boards on an existing test vehicle $\mathrm{e}^{5,40}$ ) was added to the wheel speed and acceleration signals. The amplitude of the noise was tuned to emulate measurements taken during braking tests with a full-scale vehicle. ${ }^{5}$ Accelerometer bias was omitted, since algorithms exist to estimate and correct for this online. ${ }^{46}$

The observer gains, $\mathbf{L}$ and $\mathbf{k}_{\mathbf{0}}$, were calculated in the first instance for a quarter-car (single wheel) vehicle model using the pole placement method detailed by Edwards and Spurgeon. ${ }^{42}$ The dependence of each state in equation (14) on wheel speed and longitudinal acceleration measurements in equation (15) (as described by 
the columns of $\mathbf{L}$ and $\mathbf{k}_{\mathbf{0}}$ ) was then iteratively tuned by hand to improve the reliability of the estimator.

Figure 6 shows the performance of the observer used 'in-the-loop' for a stop controlled by the sliding mode controller in equation (11). The road surface was perfectly smooth with high friction, changing to low friction after $2 \mathrm{~s}$, and the target slip was set to the peak of the $\mu$-slip curve throughout the stop. The change in friction can be identified by the wheel locking up at $2 \mathrm{~s}$, since chamber pressure cannot be reduced fast enough to cope with the instantaneous change in friction. The wheel recovers to the demand slip after another $0.5 \mathrm{~s}$. Figure 7 shows the observer's performance on a rough $(\mathrm{IRI}=20 \mathrm{~m} / \mathrm{km})$, high friction surface $\left(\mu_{o}=0.9\right)$. Note the dynamic variation in the tyre force caused by vertical vibration of the vehicle in response to road roughness. In both cases, the observer accurately tracks the true tyre forces, responding quickly to changes in force levels. Further discussion about this observer can be found in Miller and Cebon, ${ }^{22}$ and Miller. ${ }^{40}$ The output of the observer will be used in the surface identification algorithm that will be described next (see Figure 1).

\section{Optimal slip point estimation}

\section{Background}

Knowing the slip-friction characteristics of the tyre-road system facilitates selecting the maximum-braking point as a set point for the slip controller. However, a tyre of a given specification can have large variations in the parameters describing its slipfriction curve on different surfaces, even when the nominal friction of the surfaces is the same. Figure 8 shows the experimental slip curves of 295/75|275/80 R22.5 tyres tested using the UMTRI Mobile Tire Tester, which tows a tyre over a road surface, 
and the same tyres tested using the CALSPAN TIRF belt testing machines, as reported in Pottinger et al. ${ }^{47}$ and Anon. ${ }^{48}$ Although testing methods differed slightly between the two sets of data, the results highlight the uncertainty in the shape of the tyre curve for a given tyre.

The effect of the four parameters describing the UMTRI tyre model $\left(C_{o}, \mu_{o}, \mu_{f}\right.$, and $V_{f}$ ) on the location of the peak of the slip curve is shown in Figure 9. The parameters were each changed over a range of values that could reasonably be seen in a truck tyre on different surfaces. Figure 9 emphasises that all four parameters have a measurable influence on the location of the optimal slip point.

Surface identification algorithms use curve fitting techniques to regress a tyre model, given data points of braking force and wheel slip. However, many algorithms presented in the literature focus on estimating only the parameter describing the 'Coulomb friction' level. Occasional exceptions, such as Alvarez et al., ${ }^{28}$ estimate just a subset of the total number of parameters needed to describe the tyre curve. As Figures 8 and 9 show, the variability of the parameters for a tyre of a given specification may cause errors in the identification of the peak of the slip curve if only a subset of the parameters is estimated. This results in a loss of braking performance, since a slip value other than the optimal value may be used as the set point for the slip controller.

It was decided to estimate all four parameters online at once, to establish the best possible surface identification performance achievable if calculation efficiency was not considered. Omissions of any of the parameters from an estimation algorithm would yield lower accuracy than the results that will be presented here. Following this, a second algorithm will be presented that is less computationally expensive, though also less accurate, and better lends itself to online implementation. 


\section{Nonlinear estimation}

Estimation algorithm. Linear least squares regression techniques were preferred for the task of curve fitting, because this form of maximum likelihood estimator is suitable for multiple-variable regressions where the random effects are associated with the measurements of the response variable ${ }^{49,50}$ However, $V_{f}$ appears nonlinearly in the tyre model (equation (7) for $\mu$ ), and so linear least squared regression techniques could not be used for the estimator. Instead, a nonlinear least squares regression was performed using the LSQCURVEFIT command in Matlab and the objective function, $J$, given by

$$
J=\frac{1}{N} \sum_{k=1}^{N} \frac{1}{2}\left(F_{x}(k)-\hat{F}_{x}(k)\right)^{2}
$$

where $N$ is the total number of data points being used for the evaluation; $F_{x}$ was determined using the sliding observer from the section "Sliding mode force observer"; $\hat{F}_{x}$ was found using the assumed parameters and equations (5) to (10); and the true vehicle speed was assumed to be known. A Levenberg-Marquart algorithm was chosen in LSQCURVEFIT, because it is more robust than the typical Gauss-Newton approach, particularly when starting far off the final minimum. ${ }^{50}$

A flow chart describing the full estimation algorithm is shown in Figure 10. Data points were collected at $500 \mathrm{~Hz}$ (the cycling frequency of the voltage input boards on an existing test vehicle $\mathrm{e}^{5,40}$ ) and the regression was performed every $0.2 \mathrm{~s}$. It was found that the regression algorithm worked best when it had information from the nonlinear part of the slip curve, where curves for different surfaces are more distinct. But, when regulating the wheel slip to the peak of the curve, the algorithm had no information to infer the longitudinal stiffness, $C_{o}$. Since only small changes in the tyre 
stiffness were expected during a stop, the first 100 data points from a stop, when the slip is rising in the linear part of the $\mu$-slip curve, were saved. These points were used throughout the stop along with the 100 sample points preceding each regression, which should add information from the peak of the tyre curve. Keeping the first 100 data points from a stop was preferred over retaining the estimate of the longitudinal stiffness outputted by the algorithm at the beginning of the stop, because it is possible for that initial estimate of $C_{o}$ to be in error.

To prevent LSQCURVEFIT from finding minima that did not describe physically realistic road surfaces, the solver was run with the following constraints, based on data collected from UMTRI ${ }^{41}$

$0 \leq \mu_{o} \leq 1.5, \quad 1.05 \leq \frac{\mu_{o}}{\mu_{f}} \leq 3.5, \quad 0 \leq V_{f} \leq 15, \quad 0 \leq C_{o} \leq 3 \times 10^{5} \mathrm{~N}$ In addition, the coefficients were initialised to those for a low friction (icy) surface and an unladen vehicle, which was considered the safest approach, because this is the situation when the wheels are most likely to lock up. However, the algorithm was found to be relatively insensitive to the initialization values.

The optimal slip point was found using the MAX command in Matlab with the regressed tyre curve to find the maximum value of $F_{x}$ on the curve. The result from the MAX command was used as the demand slip for the wheel slip controller. The optimal slip point was initialised to 0.2 for the first iteration of the surface identification algorithm, so that the controller would force the wheel slip to reach the nonlinear part of the curve on most surfaces (see Figure 9), aiding identification.

When slowing a vehicle, a transition between two surfaces of very different friction properties can happen mid-stop. In these cases, the location of the optimal slip 
point can change swiftly and drastically, and the first 100 data points from a stop, as well as several of the data points collected immediately before the regression, can no longer be used to identify the surface. Algorithms exist for detecting surface changes, such as the CUSUM algorithm presented in Gustafsson. ${ }^{25}$ However, these algorithms rely on error accumulation, slowing reaction times. An alternative algorithm was devised here that looked at changes in $F_{x}$, normalised by the static weight carried by the wheel, $F_{z}$. If a change of this ratio greater than 0.1 was detected between the mean from the current 100 data points and the mean from the previous 100 data points, the first 100 data points from the stop were discarded, and the last 30 data points preceding the current regression were kept for the remainder of the stop (see Figure 11). This approach gave information from deep in the nonlinear part of the slip curve when transitioning from a high friction surface to a low friction surface, and information from the linear part of the curve when transitioning from a low friction surface to a high friction surface. The choice of 30 data points was found through trial and error to provide a good balance between retaining useable information from the new surface and removing information from the old surface for various scenarios of the friction changing at different times within the sampling interval. The time range covered by the 30 data points is roughly the time taken for the wheel to lock up when transitioning from a low- to a high-friction surface, and is specific to the acquisition range and frequency used here.

False positives were detected by the surface change algorithm during initial simulations on very rough roads. To mitigate this problem, an accelerometer was placed on the body of the vehicle with its axis oriented in the vertical direction. Only one accelerometer was used to minimise the number of sensors added, and the accelerometer was placed on the body because body-bounce motions cause more 
significant changes in dynamic tyre forces over longer periods of time than wheel-hop motions. ${ }^{36}$ The change in load as predicted by the accelerometer was added to the nominal static wheel load over each wheel to approximate the dynamic tyre forces, as illustrated in Figure 12.

Estimator performance. The performance of the estimator used 'in-the-loop' (see Figure 1) on a simulated vehicle undergoing a slip-controlled stop using the sliding mode controller and tyre force observer is shown in Figure 13. The stop was performed on a high friction $\left(\mu_{o}=0.9\right)$, smooth $\operatorname{road}(\mathrm{IRI}=0 \mathrm{~m} / \mathrm{km})$ that transitioned to a low friction $\left(\mu_{o}=0.2\right)$, smooth road just after $2 \mathrm{~s}$. The brake gain was assumed to be known (an estimator for the brake gain will be the subject of another paper), and the sensor noise described in the section "Sliding mode force observer" was included in the simulation.

The slip is driven up the slip-friction curve to the preset demand of 0.2 at the start of the stop (point A in Figure 13 a)). Thereafter, the slip curve is accurately regressed (point B and Figure $13 \mathrm{~b}$ )), except at the highest levels of slip on the nonlinear part of the curve, over which no force-slip data is available. The vehicle hits the icy surface $2 \mathrm{~s}$ into the stop (point $\mathrm{C}$ and Figure $13 \mathrm{c}$ )). The algorithm identifies the change in longitudinal force over the subsequent regression cycle, discards all data points except those at a slip of 1 and defaults to a demand slip value of 0.2 (point D). The slip curve is identified on the next cycle, before the chamber has time to dump its air, and the demand slip approaches the optimal slip for the duration of the stop.

The performance of the estimator in a simulated stop with sliding mode slip control on a low friction $\left(\mu_{o}=0.2\right)$, rough road (IRI $\left.=20 \mathrm{~m} / \mathrm{km}\right)$ that transitions to a high friction $\left(\mu_{o}=0.9\right)$, rough road after $2 \mathrm{~s}$ is shown in Figure 14. The demand slip 
overshoots the optimal demand slip during the first estimation cycle (point A in Figure 14 a)), due to the preset slip demand of 0.2 , but quickly returns to the optimal slip point once the surface is identified (see point B and Figure $14 \mathrm{~b}$ )). After $2 \mathrm{~s}$ (point $\mathrm{C}$ and Figure $14 \mathrm{c})$ ), the vehicle hits the high friction surface. The surface change is detected at the end of the estimation period, and the demand is set to the preset demand slip of 0.2 to bring the wheel slip near the optimal slip point during the next cycle (point D).

Beyond this point, the demand slip is regulated near the optimal slip point, but the accuracy of the slip controller degrades slightly on the high friction, rough road. The roughness caused larger variations in longitudinal force on the high friction road, and as a result, the estimation algorithm chooses incorrect parameters for the slip curve at some points, as illustrated in Figure $14 \mathrm{~d}$ ). Nonetheless, this example shows that the algorithm is reasonably robust to road roughness and sudden changes in surface friction. It should be noted that the change detection algorithm may not recognise a surface whose friction changes slowly, as with a gradual friction gradient. In this case, it may be better to supplement the estimator with a detector based on error-accumulation, such as the CUSUM algorithm mentioned earlier.

The estimator took up to $200 \mathrm{~ms}$ to perform each regression on a computer with a $2.67 \mathrm{GHz}$ processor. This may not be practical for real-time implementation using conventional ECUs. Although it is reasonable to expect onboard processors to reach speeds of $2.67 \mathrm{GHz}$ in the near future, and that a made-for-purpose, optimised algorithm would run faster, it was of interest to see whether a more computationally efficient algorithm could be developed. 


\section{Recursive least squares estimation}

Estimation algorithm. Full nonlinear least squares regressions are computationally expensive and do not lend themselves readily to online implementation using current onboard computer power. If $V_{f}$ was known, however, equations (5) to (9) describing the UMTRI tyre model could be reformulated to use common recursive least squares regression techniques. In addition, the analysis here assumes that $C_{o}$ can be found using information retrieved from the linear part of the slip curve during normal driving, using algorithms such as those described in Gustaffson. ${ }^{25}$

If the braking force equation is expanded as

$F_{x}=\left(\mu_{f}+\left(\mu_{0}-\mu_{f}\right) e^{-\frac{v_{x}-\omega_{v} r_{f}}{V_{f}}}\right) F_{z}-\frac{\left(\mu_{f}^{2}+\mu_{f}\left(\mu_{0}-\mu_{f}\right) e^{-\frac{v_{x}-\omega_{v} r_{x}}{V_{f}}}+\left(\mu_{0}-\mu_{f}\right)^{2} e^{-\frac{2\left(v_{x}-\omega_{v_{r}, f}\right)}{V_{f}}}\left(F_{z}\right)^{2}(1-\lambda)\right.}{4 C_{0} \lambda}$

then the unknown coefficients: $\mu_{o}$ and $\mu_{f}$ can be parameterised against the known variables as

$$
\boldsymbol{y}=\boldsymbol{\theta}_{r}^{t} \boldsymbol{a}_{r}
$$

where,

$$
\begin{aligned}
& \boldsymbol{y}=F_{x}
\end{aligned}
$$

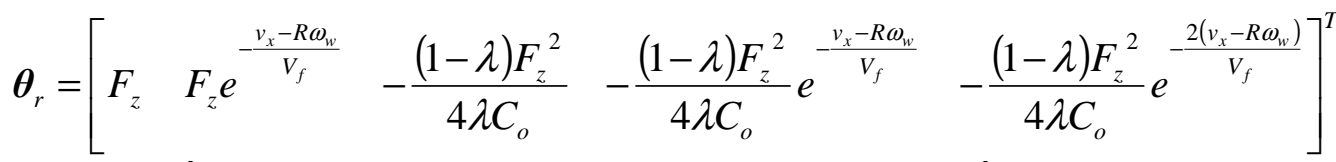

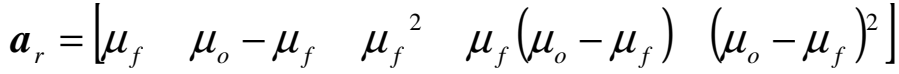

Equations (19) to (21), as derived above, were used in the standard recursive least squares formulation, given by ${ }^{51}$ 


$$
\begin{aligned}
\hat{\boldsymbol{a}}_{\boldsymbol{r}}(n) & =\hat{\boldsymbol{a}}_{\boldsymbol{r}}(n-1)+\boldsymbol{k}_{e}(n)\left[\boldsymbol{y}(n)-\boldsymbol{\theta}_{r}(n) \hat{\boldsymbol{a}}_{r}(n-1)\right] \\
\boldsymbol{k}_{e}(n) & =\frac{\mathbf{P}(n-1) \boldsymbol{\theta}_{r}(n)}{\boldsymbol{\varphi}+\boldsymbol{\theta}_{r}(n) \mathbf{P}(n-1) \boldsymbol{\theta}_{r}(n)} \\
\mathbf{P}(n) & =\frac{\mathbf{P}(n-1)}{\boldsymbol{\varphi}}-\frac{\boldsymbol{k}_{e}(n) \boldsymbol{\theta}_{r}(n) \mathbf{P}(n-1)}{\boldsymbol{\varphi}}
\end{aligned}
$$

where $n$ is a given time step, $\boldsymbol{k}_{\boldsymbol{e}}$ is the recursive gain, $\mathbf{P}$ is the covariance matrix, and $\varphi$ is the forgetting factor. The recursive scheme was found to run best with a constant forgetting factor of 0.97 , which was tuned offline, and without bounds on $\mu_{o}$ and $\mu_{f}$.

Estimator performance. Results of using the recursive estimation algorithm inthe-loop are shown for a simulated stop on a high friction $\left(\mu_{o}=0.9\right)$, smooth road (IRI $=0 \mathrm{~m} / \mathrm{km}$ ) in Figure 15 . The correct values of $C_{o}$ and $V_{f}$ were fed to the algorithm in the simulation. After an initial transient response of approximately $0.75 \mathrm{~s}$, the estimated optimal slip point tracks the true optimal slip point for most of the stop. Figure $15 \mathrm{~b}$ ) and c) show that the recursive scheme provides reasonable estimates for the values of $\mu_{o}$ and $\mu_{f}$, except at around $2 \mathrm{~s}$ into the stop, where a detrimental combination of sensor noise occurred. However, the algorithm could not be used on a low friction surface, despite having knowledge of the correct values of $C_{o}$ and $V_{f}$, because errors in the estimation frequently caused $\mu_{o}$ or $\mu_{f}$ to be estimated as zero. Moreover, the variables in the recursive algorithm could not be tuned to achieve a better compromise between accuracy and estimation speed.

Despite the recursive least squares algorithm being inadequate for low friction surfaces, and hence unsuitable for emergency braking applications, its robustness was explored further for illustrative purposes. Figure 16 shows the performance of the recursive estimator on a high friction $\left(\mu_{o}=0.9\right)$, rough $\operatorname{road}(\mathrm{IRI}=20 \mathrm{~m} / \mathrm{km})$. The 
forgetting factor and the initialization of the covariance matrix on the estimator had to be 'detuned' slightly for it to converge under these conditions. The accuracy of the estimated optimal slip point degraded on the rough surface relative to the smooth surface. Furthermore, when looking at the estimates of $\mu_{o}$ and $\mu_{f}$ in Figure 16 b) and c), the algorithm can be seen to take around $2 \mathrm{~s}$ to converge, due to the new tuning.

The simulated performance of the estimator on a high friction $\left(\mu_{o}=0.9\right)$, smooth road (IRI $=0 \mathrm{~m} / \mathrm{km})$ with a $30 \%$ error in the assumed values of $V_{f}$ and $C_{o}$ is shown in Figure 17. The errors resulted in $\mu_{f}$ being under-estimated and $\mu_{o}$ taking a long time to converge, as can be seen in Figure $17 \mathrm{~b}$ ) and c). This caused the optimal slip point to be under-estimated as well, as shown in Figure 17 a).

The recursive estimator cycled much faster in simulations than the full nonlinear algorithm. Each estimation cycle took less than $0.5 \mathrm{~ms}$ in Matlab when used in-the-loop on a computer with a $2.67 \mathrm{GHz}$ processor, making the recursive scheme more feasible for real-time implementation using conventional ECUs. However, the recursive estimator was not robust to variations in the road surface and tended to converge relatively slowly.

\section{Conclusions}

(1) A sliding mode braking force observer was derived assuming a random walk model for the force and using measurements of longitudinal vehicle acceleration, wheel speed, and brake pressure. The sliding mode observer was robust to surface changes and road roughness in simulations.

(2) A nonlinear least squares approach was used successfully to regress all four coefficients needed to describe slip curves with the UMTRI tyre model given 
combinations of estimated force and wheel slip. The algorithm passed demand slip points to the slip controller that were close to the optimal slip point when used in-the-loop in simulations on roads of differing frictions and levels of road roughness. The algorithm was able to respond to sudden changes in surface friction characteristics within $0.2 \mathrm{~s}$.

(3) A computationally efficient, recursive least squares estimator was derived for tyre curve regression, assuming $C_{o}$ and $V_{f}$ were known. While the resulting algorithm performed reasonably well on smooth, high friction surfaces, it was not robust to variations in the parameters, surface roughness, or the level of surface friction.

(4) The full nonlinear algorithm estimated all parameters of the tyre curve, but is too computationally expensive, and may not be practical for real-time implementation using common ECUs in its current form. It is expected that a made-for-purpose, optimised nonlinear solver would run faster than Matlab's LSQCURVEFIT. Consequently, future refinement is recommended to speed up the nonlinear scheme, such that it can be run on a vehicle's ECU.

(5) The algorithms were presented for a quarter-car model. As future work, a more complex, six-wheeled model of the experimental semi-trailer will be used to provide more information for the friction estimator. The optimal slip point could be estimated at each wheel individually with the current algorithm, averaging the estimates over all wheels, or the observed tyre forces from the more complex model could be fed into a common estimation algorithm. Additionally, the leading axles could provide preview information for the following axles, allowing the slip control strategy to be modified more quickly in the event of a sudden change in surface friction. 
(6) Further future work includes incorporating velocity- and additional parameter estimation (eg. for the brake gain) into the algorithm in order to complete the block diagram shown in figure 1.

\section{Acknowledgements}

The authors would like to thank the members of the Cambridge Vehicle Dynamics Consortium (CVDC), and the Gates Cambridge Trust for their parts in funding this work. At the time of writing, the CVDC had the following industrial members: Anthony Best Dynamics; Camcon; Denby Transport; Firestone Industrial Products; Goodyear Tyres; Haldex; SIMPACK; Mektronika Systems; MIRA; Poclain Hydraulics; SDC Trailers; Tinsley Bridge; Tridec BV; Volvo Trucks; and Wincanton.

\section{References}

1. Anon. Delivering the economy. The Independent / RAM Business Information, UK, April 18, 2007.

2. Dunn A and Hoover R. Class 8 truck tractor braking performance improvement study, report 1, straight line stopping performance on a high coefficient of friction surface. Transportation Research Center Inc. / National Highway Traffic Safety Administration, East Liberty, OH, 2004.

3. Jermakian JS. Crash avoidance potential of four large truck technologies. Insurance Institute for Highway Safety, Arlington, VA, 2010.

4. Anon. Traffic safety facts, 2007. National Highway Traffic and Safety Administration, US Department of Transportation, 2008.

5. Kienhofer F and Cebon D. An investigation of ABS strategies for articulated vehicles. Proc. of the 8th international symposium on heavy vehicle weights and dimensions, Misty Hill, South Africa, 2004.

6. Anon. Bosch automotive handbook. $5^{\text {th }}$ edn. Stuttgart: Robert Bosch GmbH, 2000.

7. Emereole OC. Antilock performance comparison between hydraulic and electromechanical brake systems. Dissertation, University of Melbourne, Australia, 2003.

8. Miller J, Kienhofer F and Cebon D. The design and evaluation of an alternative heavy vehicle braking system, 9th International Symposium on Advanced Vehicle Control, Kobe, Japan, 2008.

9. Miller J and Cebon D. Modelling and performance of a pneumatic brake actuator. Proc. of the IMECHE Part C: J of Mech Eng Sci. 2012; 226: 2077-2092.

10. Best MC, Newton AP and Tuplin S. The identifying extended Kalman filter: parametric system identification of a vehicle handling model. IMECHE Part $K$ - J. of Multi-Body Dyn. 2007; 21: 87-98.

11. Best MC, Gordon TJ and Dixon PJ. An extended adaptive Kalman filter for realtime state estimation of vehicle handling dynamics. Veh. Sys. Dyn. 2000; 34: $57-75$.

12. Bevly DM and Parkinson B. Cascaded Kalman filters for accurate estimation of multiple biases, dead-reckoning navigation, and full state feedback control of ground vehicles. IEEE Trans. on Ctl. Sys. Tech. 2007; 15: 199-208. 
13. Kimbrough S and Datla K. An effective means for implementing wheelslip control without a ground speed sensor. Veh. Sys. Dyn. 1996; 25: 327-339.

14. Ray LR. Nonlinear tire force estimation and road friction identification: simulation and experiments. Automatica. 1997; 33: 1819-1833.

15. Shim T, Chang $\mathrm{S}$ and Lee $\mathrm{S}$. Investigation of sliding-surface design on the performance of sliding mode controller in antilock braking systems. IEEE Trans. on Veh. Tech. 2008; 57: 747-759.

16. Hong $D$ et al. Development of a vehicle stability control system using brake-bywire actuators. ASME J. of Dyn. Sys., Meas., and Ctl. 2008; 130: 1-9.

17. Unsal $C$ and Kachroo P. Sliding mode measurement feedback control for antilock braking systems, IEEE Trans. on Ctl. Sys. Tech. 1999; 7: 271-281.

18. Drakunov $\mathrm{S}$ et al. ABS control using optimum search via sliding modes. IEEE Trans. on Ctl. Sys. Tech. 1995; 3: 79-85.

19. Choi SB, Cho MS and Wereley NM. Wheel-slip control of a passenger vehicle using an electrorheological valve pressure modulator. IMECHE Part D - J. of Auto. Eng. 2006; 220: 519-529.

20. Ribbens WB and Fredricks R. A sliding mode observer based ABS for aircraft and land vehicles. SAE paper 2003-01-0252, 2003.

21. Ribbens WB, Ribbens JA and Fredricks R. Sliding mode observer-based ABS offers advantages for HD truck applications. Proc. of the SAE 2007 commercial vehicle engineering congress \& exhibition. 2007; 2007-01-4243: $1-8$.

22. Miller JI and Cebon D. A high performance pneumatic braking system for heavy vehicles. Veh. Sys. Dyn. 2010; 48: 373-392.

23. Cadiou JC, El Hadire A and Chikhi F. Non-linear tyre forces estimation based on vehicle dynamics observation in a finite time. IMECHE Part D - J. of Auto. Eng. 2004; 218: 1379-1392.

24. Yoda $\mathrm{S}$ et al. Road surface recognition sensor using an optical spatial filter. Proc. of the intelligent vehicles '95 symposium, Detroit, MI, 1995, pp.253-257.

25. Gustafsson F. Slip-based tire-road friction estimation. Automatica. 1997; 33: 1087-1099.

26. Hodgson $\mathrm{G}$ and Best MC. A parameter identifying a Kalman filter observer for vehicle handling dynamics. IMECHE Part D - J. of Auto. Eng. 2006; 220: 1063-1072.

27. Yi J et al. Emergency braking control with an observer-based dynamic tire/road friction model and wheel angular velocity measurement, Veh. Sys. Dyn. 2003; 39: 81-97.

28. Alvarez L et al. Dynamic friction model-based tire-road friction estimation and emergency braking control. ASME J. of Dyn. Sys., Meas., and Ctl. 2005; 127: 22-32.

29. Patel N, Edwards C and Spurgeon SK. Tyre-road friction estimation - a comparative study. IMECHE Part D - J. of Auto. Eng. 2008; 222: 2337-2351.

30. Patel N, Edwards C and Spurgeon SK. Optimal braking and estimation of tyre friction in automotive vehicles using sliding modes. Intl. Journal Sys. Sci. 2007; 38: 901-912.

31. Yi K, Hedrick K and Lee SC. Estimation of tire-road friction using observer based identifiers. Veh. Sys. Dyn. 1999; 31: 233-261.

32. Pasterkamp WR and Pacejka HB. The tyre as a sensor to estimate friction, Veh. Sys. Dyn. 1997; 27: 409-422. 
33. Anon. Mechanics of heavy duty truck systems course notes. Course on mechanics of heavy duty truck systems, University of Michigan Transportation Research Institute, 2007.

34. Pacejka HB. Tire and Vehicle Dynamics, $2^{\text {nd }}$ Ed. SAE International, Elsevier, Oxford, UK, 2006.

35. Fancher PS et al. A factbook of the mechanical properties of the components for single-unit and articulated heavy trucks. University of Michigan Transportation Research Institute, Ann Arbor, MI, 1986.

36. Cebon D. Handbook of vehicle-road interaction. Swets \& Zeitlinger, B. V., Lisse, Netherlands, 1999.

37. ISO 8608:1995. Mechanical vibration - road surface profiles - reporting of measured data.

38. Sayers M and Gillespie T. Guidelines for conducting and calibrating road roughness measurements. University of Michigan Transportation Research Institute, Ann Arbor, MI, 1986.

39. Cheng C et al. High-speed optimal steering of a tractor-semitrailer. Veh. Sys. Dyn. 2011; 49: 561-593.

40. Miller J, Advanced braking systems for heavy vehicles. $\mathrm{PhD}$ Thesis in Eng., University of Cambridge, UK, 2010.

41. Fancher PS. Generic data for representing truck tire characteristics in simulations of braking and braking-in-a-turn maneuvers. University of Michigan Transportation Research Institute, Ann Arbor, MI, 1995.

42. Edwards C and Spurgeon SK. Sliding mode control: theory and applications, Taylor \& Francis, London, 1998.

43. Misawa EA and Hedrick JK. Nonlinear observers - a state-of-the-art survey. ASME Trans. 1989; 111: 344-352.

44. Slotine JJE, Hedrick JK and Misawa EA. On sliding observers for nonlinear systems. ASME J. of Dyn. Sys., Meas., and Ctl. 1987; 109: 245-252.

45. El-Diasty $\mathrm{M}$ and Pagiatakis S. Calibration and stochastic modelling of inertial navigation sensor errors. J. of Global Pos. Sys. 2008; 7: 170-182.

46. Bevly DM and Parkinson B. Cascaded Kalman filters for accurate estimation of multiple biases, dead-reckoning navigation, and full state feedback control of ground vehicles. IEEE Trans. on Ctl. Sys. Tech. 2007; 15: 199-208.

47. Pottinger MG et al. Force and moment properties of a small sample of tire specifications: drive, steer, and trailer with evolution from new to naturally worn-out to retreaded considered. SAE paper 982748, 1998.

48. Anon. Truck tire characterization. SAE Cooperative Research Report, CRP-11, SAE, Warrendale, PA, 1995.

49. Wonnacott TH and Wonnacott RJ. Introductory statistics, $3^{\text {rd }}$ Ed., Wiley \& Sons, New York, NY, 1997.

50. Cox MG, Forbes AB and Harris PM. Software support for metrology - best practice guide no. 4 - discrete modelling. Ver. 1.1, Centre for Mathematics and Scientific Computing, National Physical Laboratory, Teddington, UK, 2002.

51. Kiencke U and Nielsen L. Automotive control systems. $2^{\text {nd }}$ Ed. SAE International, Springer-Verlag, Heidelberg, Germany, 2000. 


\section{Tables}

Table 1. Vehicle Simulation Parameters (from Anon., ${ }^{33}$ Cebon, ${ }^{36}$ Fancher, ${ }^{41}$ measurements, and discussions with UMTRI and manufacturers)

\begin{tabular}{|c|c|}
\hline Parameter & Value \\
\hline$J_{w}$ & $13 \mathrm{~kg} \bullet \mathrm{m}^{2}$ \\
\hline$m_{U}$ & $400 \mathrm{~kg}$ \\
\hline$m_{S}$ & $1600 \mathrm{~kg}$ \\
\hline$G$ & $0.016 \mathrm{~N} \bullet \mathrm{m} / \mathrm{Pa}$ \\
\hline$r_{r}$ & $0.52 \mathrm{~m}$ \\
\hline$k_{S}$ & $500 \mathrm{kN} / \mathrm{m}$ \\
\hline$k_{t}$ & $1400 \mathrm{kN} / \mathrm{m}$ \\
\hline$c_{S}$ & $15 \mathrm{kN} \cdot \mathrm{s} / \mathrm{m}$ \\
\hline$c_{t}$ & $2 \mathrm{kN} \cdot \mathrm{s} / \mathrm{m}$ \\
\hline$C_{1}$ & 10 \\
\hline$C_{2}$ & $13345 \mathrm{~N}$ \\
\hline
\end{tabular}


Figures

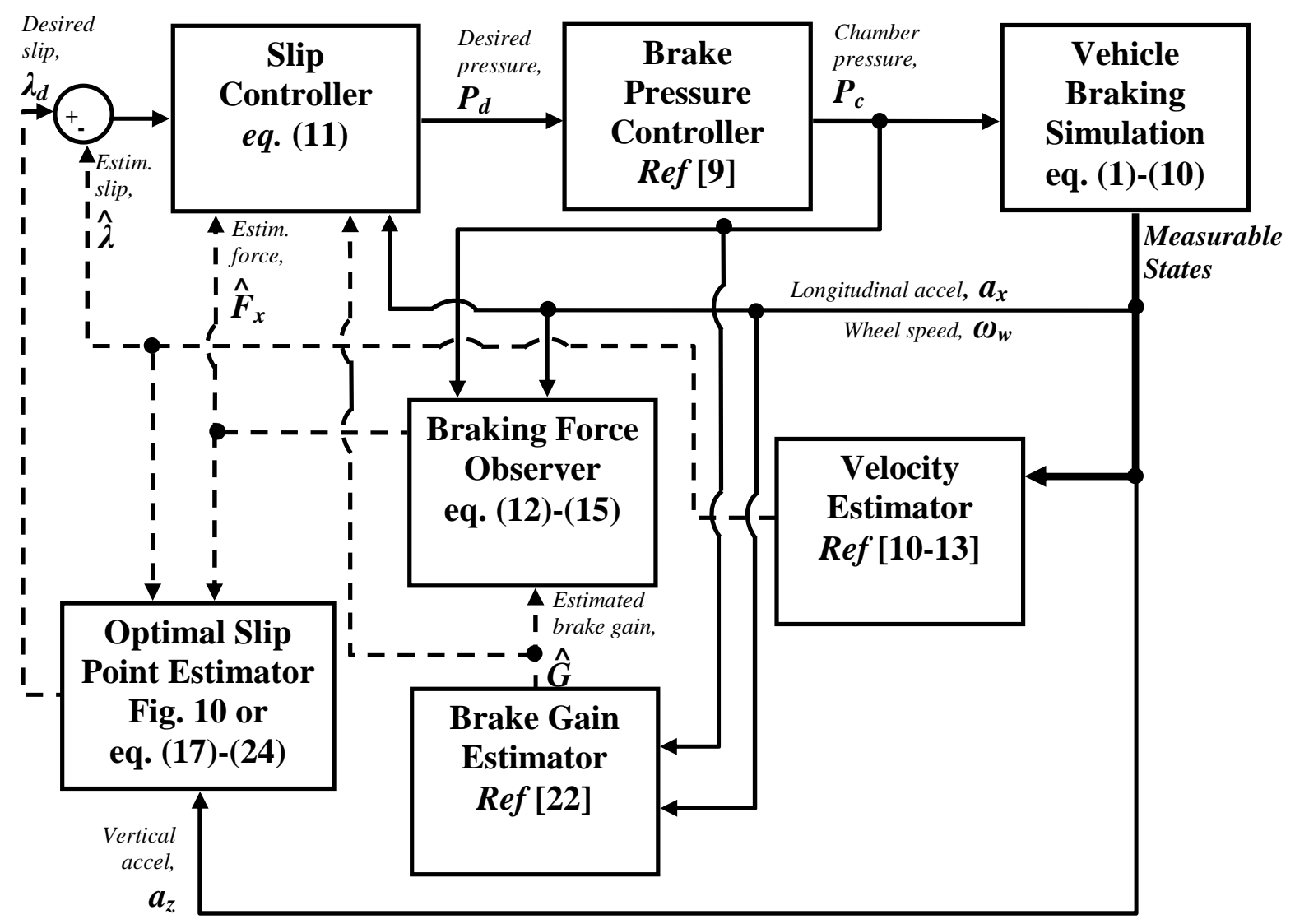

Figure 1. Block diagram of the full braking control system (solid lines denote measured signals, dashed lines denote estimated signals).

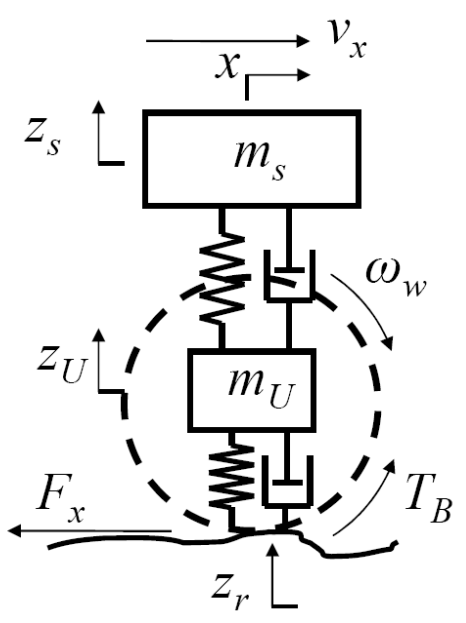

Figure 2. Quarter car vehicle model. 


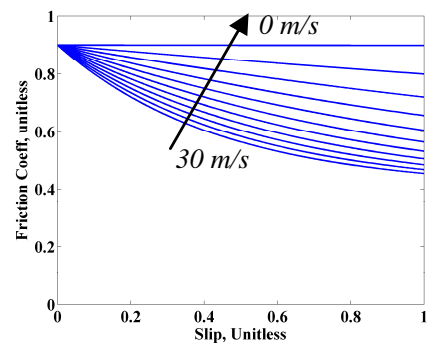

(a)

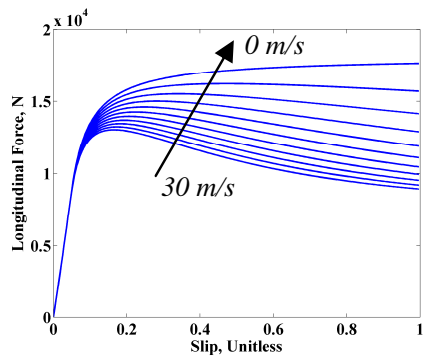

(b)

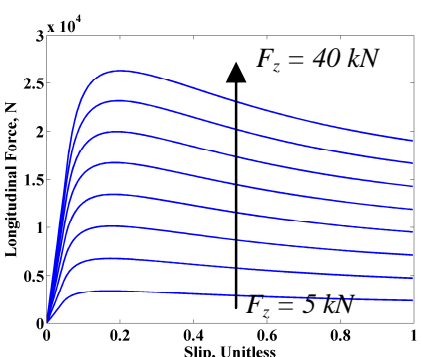

(c)

Figure 3. Parametric analysis of the UMTRI tyre model.

(a) Change in $\mu(\lambda)$ with $v x$ and $\lambda$

(b) Change in $F x(\lambda)$ with $v x$ and $\lambda$

(c) Change in $F x(\lambda)$ with $F z$ and $\lambda$

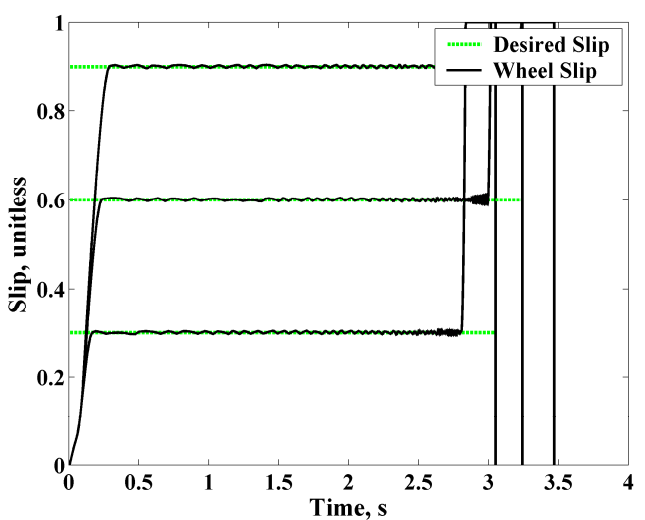

(a)

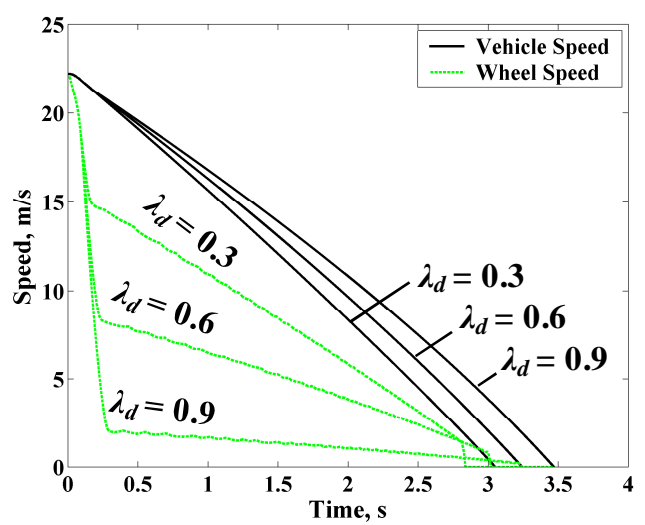

(b)

Figure 4. Sliding mode slip controlled stops on a smooth (IRI $=0 \mathrm{~m} / \mathrm{km}$ ), high friction $\left(\mu_{o}=0.9\right)$ surface. Demanded slip set to $0.3,0.6$, and 0.9 .

(a) Slip time histories

(b) Speed time histories

IRI: International Road Roughness Index 


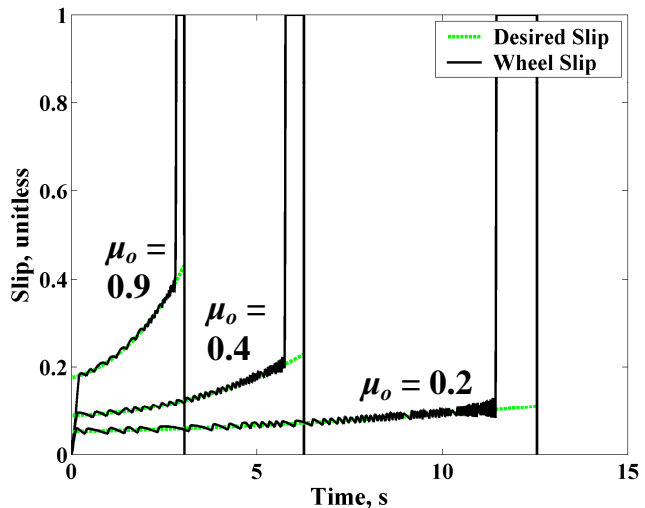

(a)

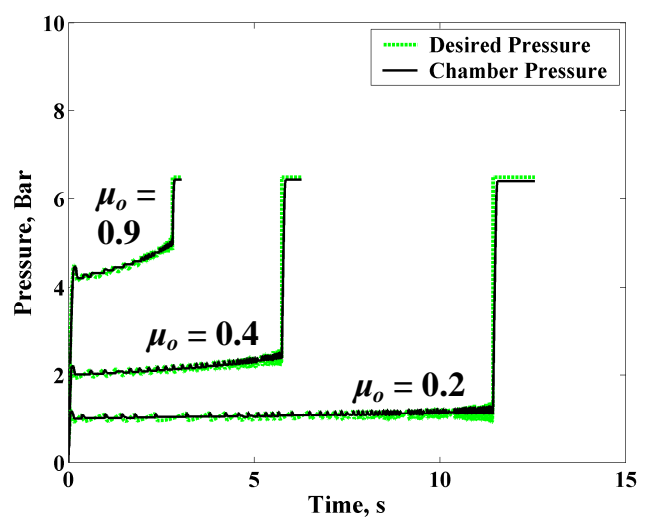

(b)

Figure 5. Sliding mode slip controlled stops on smooth (IRI $=0 \mathrm{~m} / \mathrm{km}$ ), high friction $\left(\mu_{o}=0.9\right)$, medium friction $\left(\mu_{o}=0.4\right)$, and low friction $\left(\mu_{o}=0.2\right)$ surfaces.

\section{(a) Slip time histories \\ (b) Chamber pressure time histories}

IRI: International Road Roughness Index

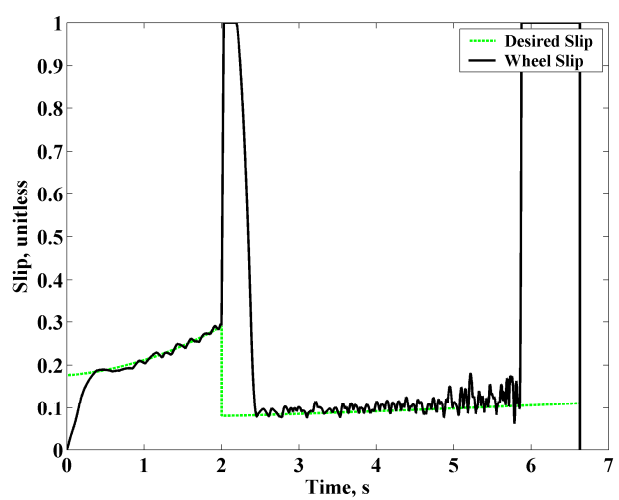

(a)

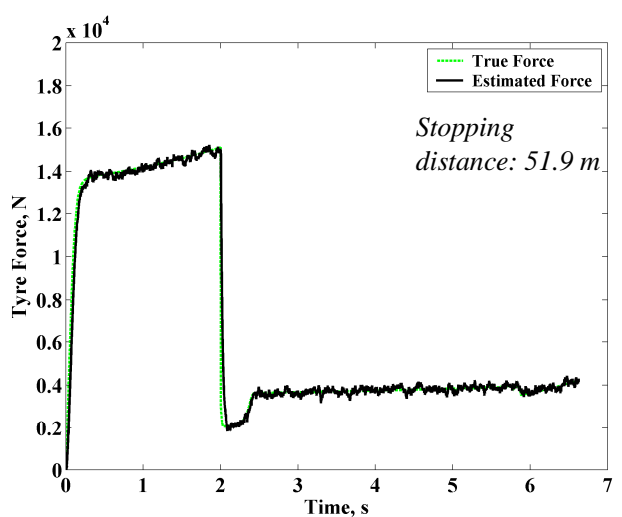

(b)

Figure 6. Simulated sliding mode observer performance on a single-wheeled model and a high friction, smooth road $\left(\mu_{o}=0.9, \mathrm{IRI}=0 \mathrm{~m} / \mathrm{km}\right)$, with a change to a low friction, smooth road $\left(\mu_{o}=0.2, \mathrm{IRI}=0 \mathrm{~m} / \mathrm{km}\right)$ after $2 \mathrm{~s}$.

(a) Slip time histories

(b) Braking force time histories

IRI: International Road Roughness Index 

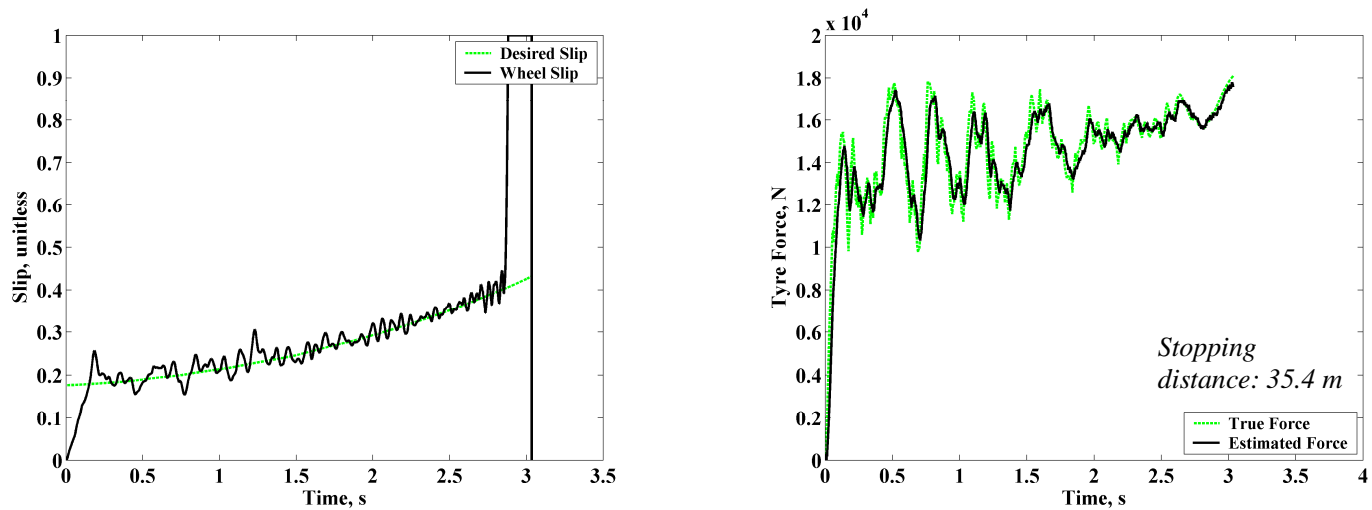

(a)

(b)

Figure 7. Simulated sliding mode observer performance on a single-wheeled model and a high friction, rough road $\left(\mu_{o}=0.9, \mathrm{IRI}=20 \mathrm{~m} / \mathrm{km}\right)$.
(a) Slip time histories
(b) Braking force time histories

IRI: International Road Roughness Index

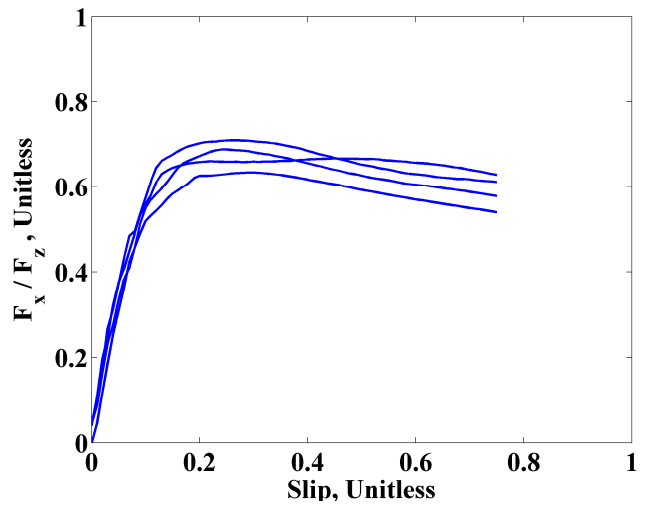

(a)

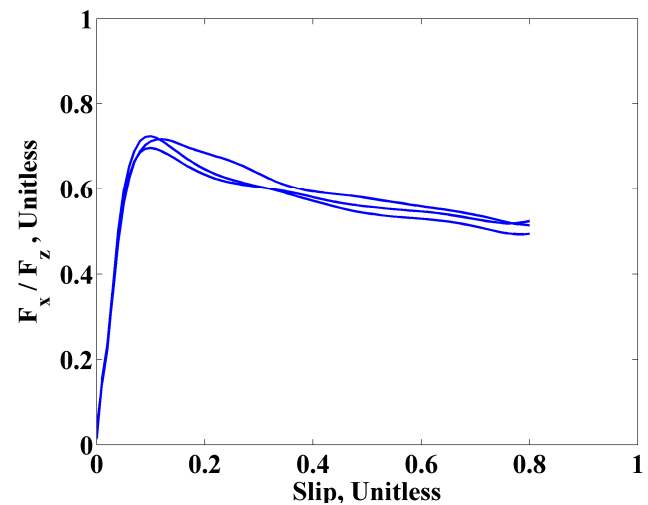

(b)

Figure 8. Sample tyre curves for 295/75|275/80 R22.5 tyres tested using different methods (each line represents an individual test), collected by Pottinger et al. ${ }^{47}$ and Anon. $^{48}$

(a) UMTRI Mobile Tyre Tester

(b) CALSPAN TIRF 


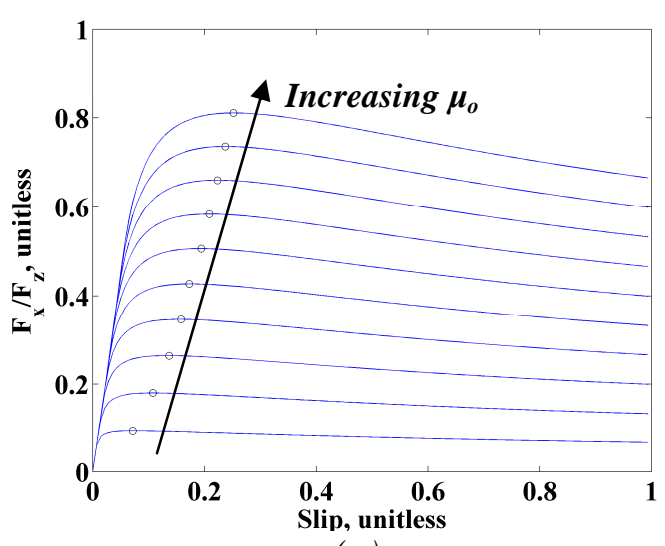

(a)

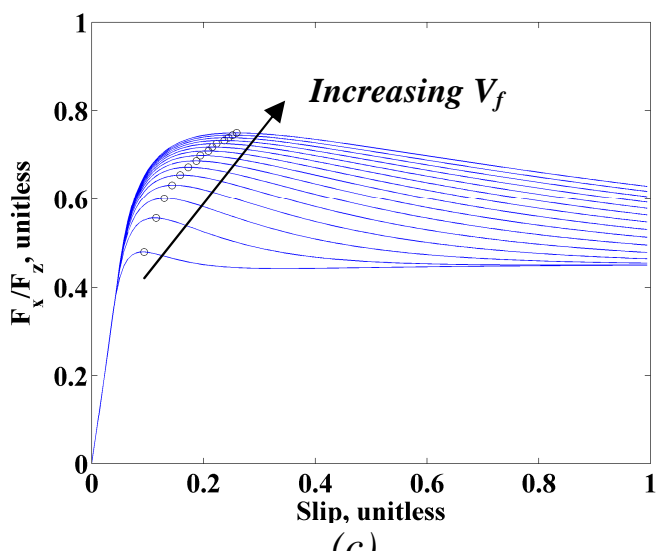

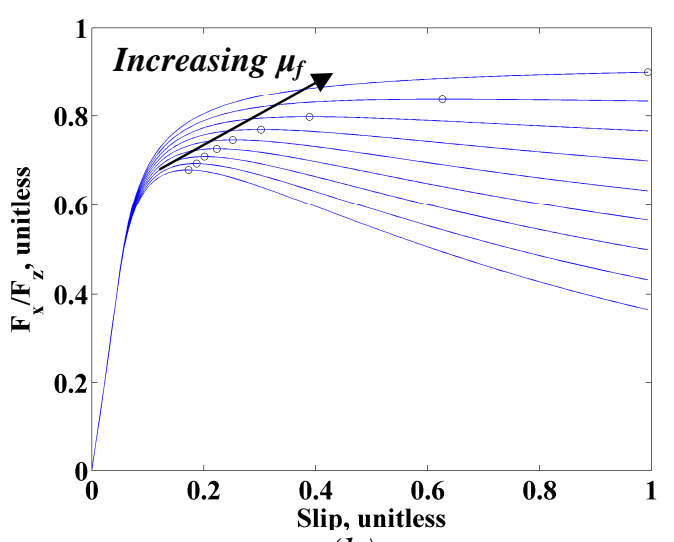

(b)

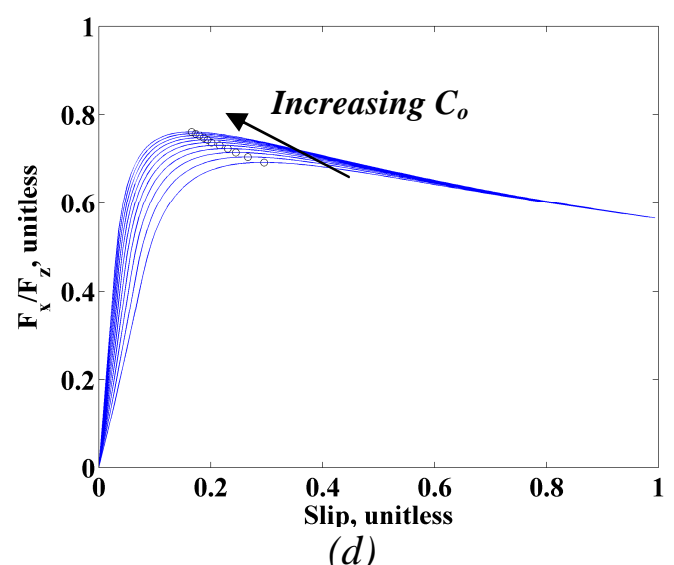

Figure 9. Influence of different parameters on the location of the optimal slip point (indicated by the circles).
(a) $\mu_{o}=0.1-1 ; \quad \mu_{f}=\mu_{o} / 2 ; \quad V_{f}=12.5 ; C_{o}=1.6 \times 10^{5} \mathrm{~N}$
(b) $\mu_{f}=0.1-0.9 ; \quad \mu_{o}=0.9 ; \quad V_{f}=12.5 ; C_{o}=1.6 \times 10^{5} \mathrm{~N}$
(c) $V_{f}=1-15 ; \quad \mu_{o}=0.9 ; \quad \mu_{f}=\mu_{o} / 2 ; \quad C_{o}=1.6 \times 10^{5} \mathrm{~N}$
(d) $C_{o}=1.0 \times 10^{5}-3.0 \times 10^{5} \mathrm{~N} ; \quad \mu_{o}=0.9 ; \quad \mu_{f}=\mu_{o} / 2 ; \quad V_{f}=12.5$ 


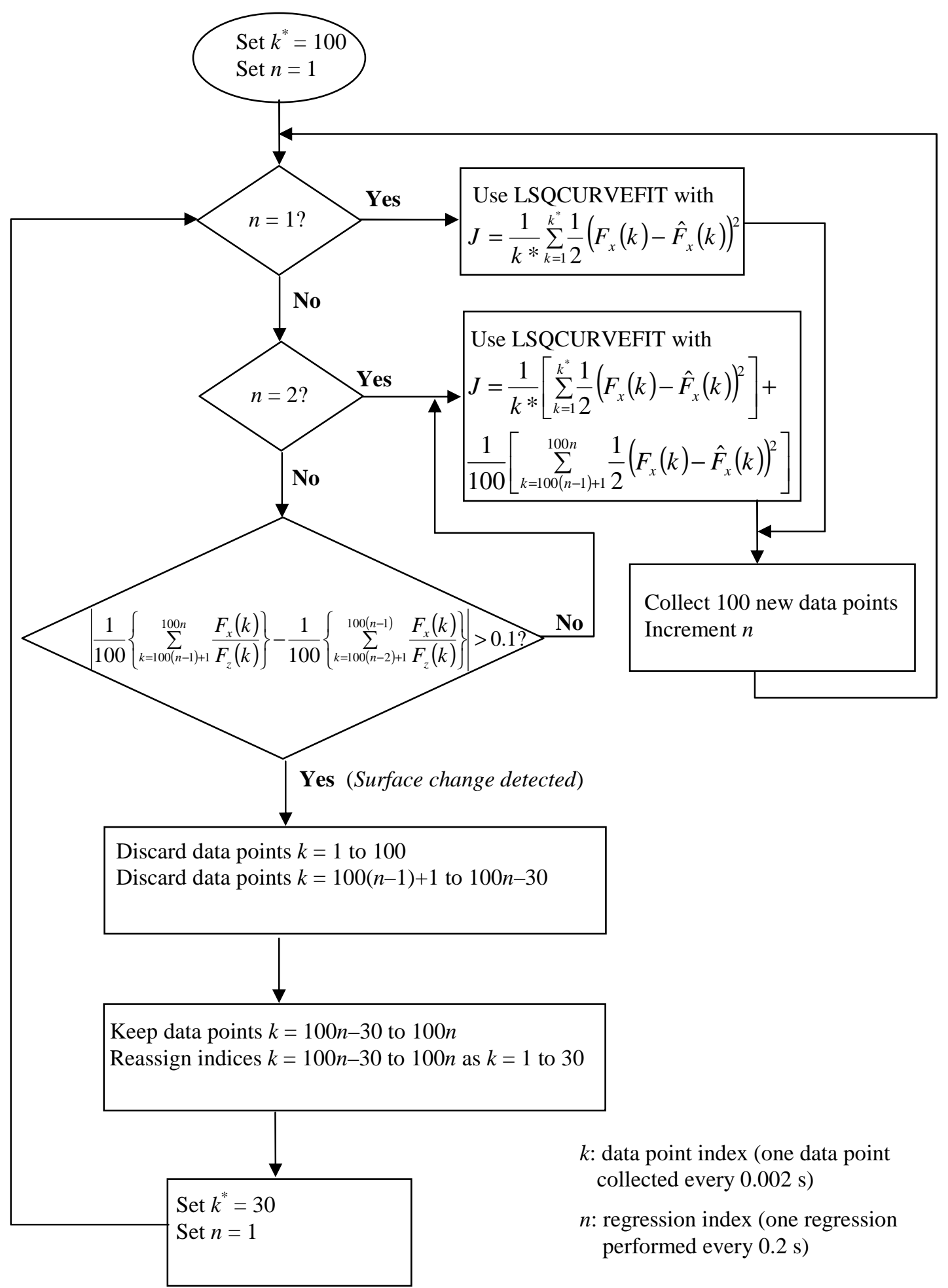

Figure 10. Flow chart for the nonlinear estimation algorithm. 

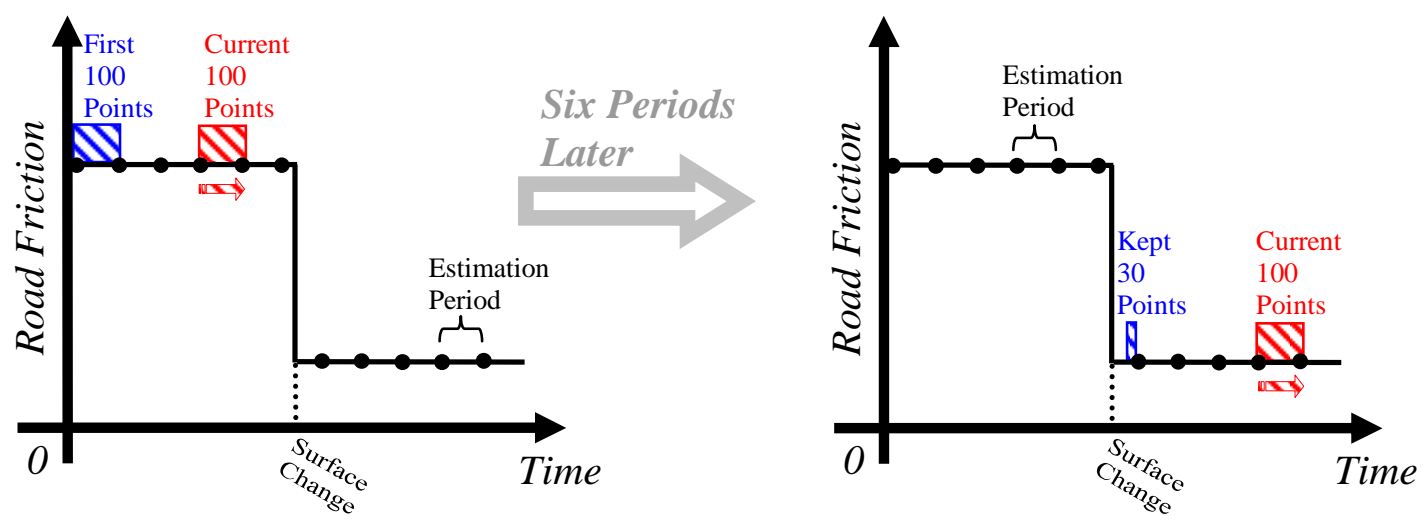

Figure 11. Diagram describing the nonlinear estimation algorithm during a surface change.

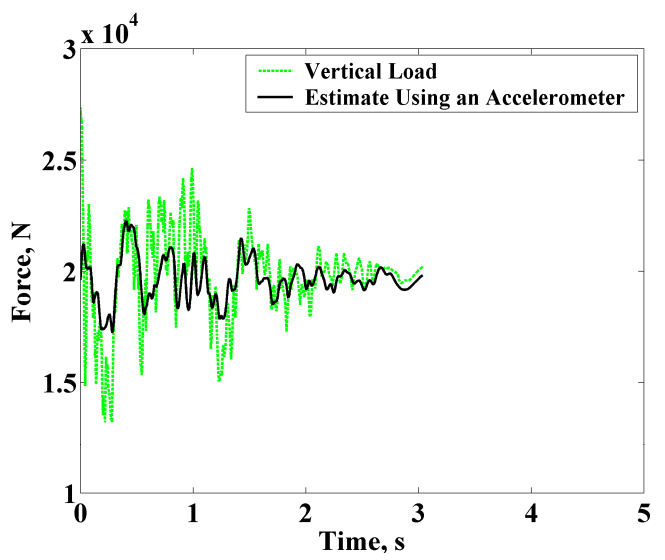

Figure 12. Approximating dynamic tyre forces using a body accelerometer on rough roads. 


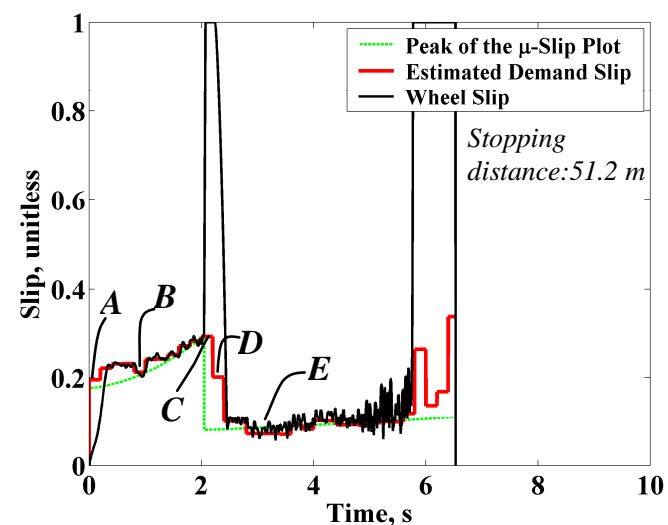

(a)

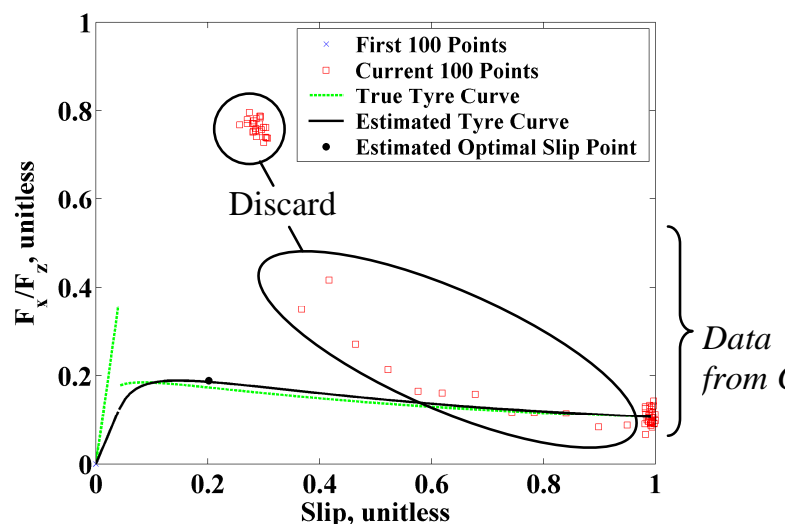

(c)

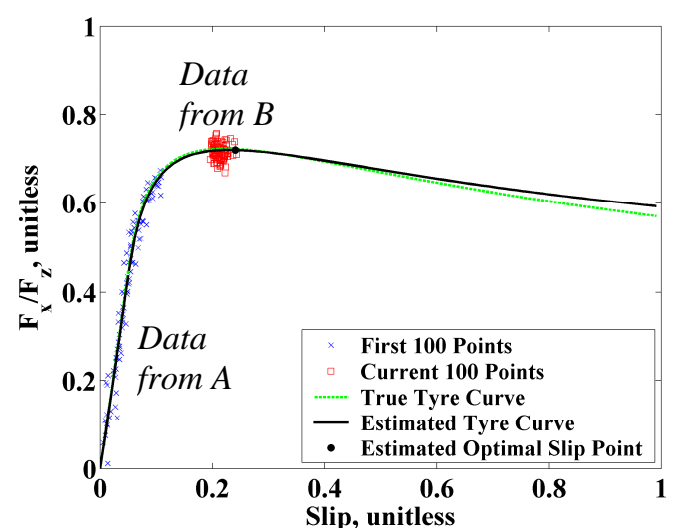

(b)

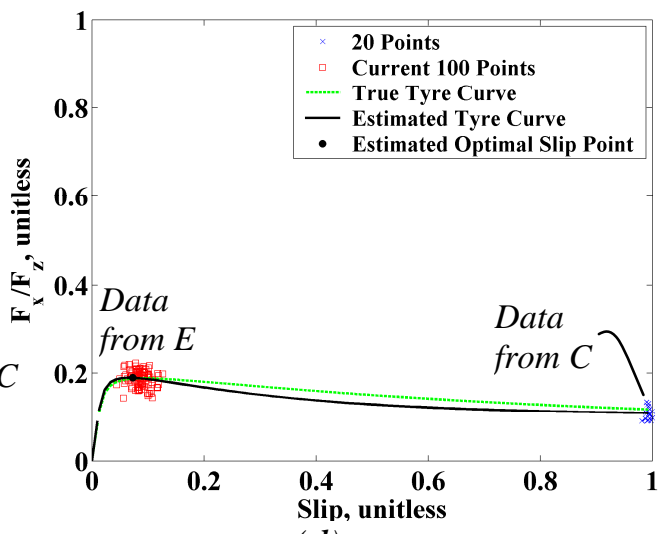

(d)

Figure 13. Simulated slip curve estimation using the nonlinear least squares algorithm on a single-wheel model and a high friction, smooth road $\left(\mu_{o}=0.9, \mathrm{IRI}=0 \mathrm{~m} / \mathrm{km}\right)$, with a change to a low friction, smooth road $\left(\mu_{o}=0.2, \mathrm{IRI}=0 \mathrm{~m} / \mathrm{km}\right)$ after $2 \mathrm{~s}$.
(a) Slip time histories
(b) Slip curve estimated at $1 \mathrm{~s}$ into the stop
(c) Slip curve estimated at $2.2 \mathrm{~s}$ into the stop
(d) Slip curve estimated at $3.2 \mathrm{~s}$ into the stop

IRI: International Road Roughness Index 


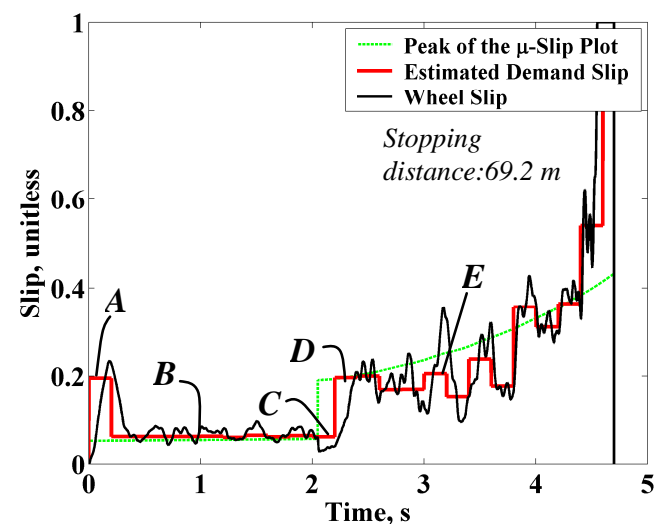

(a)

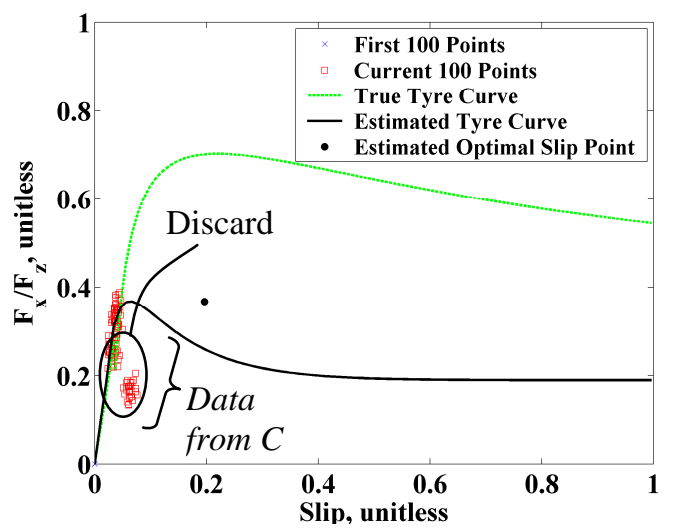

(c)

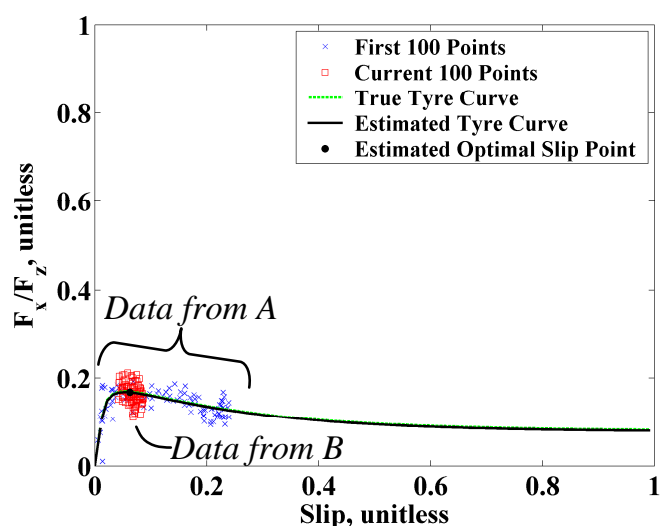

(b)

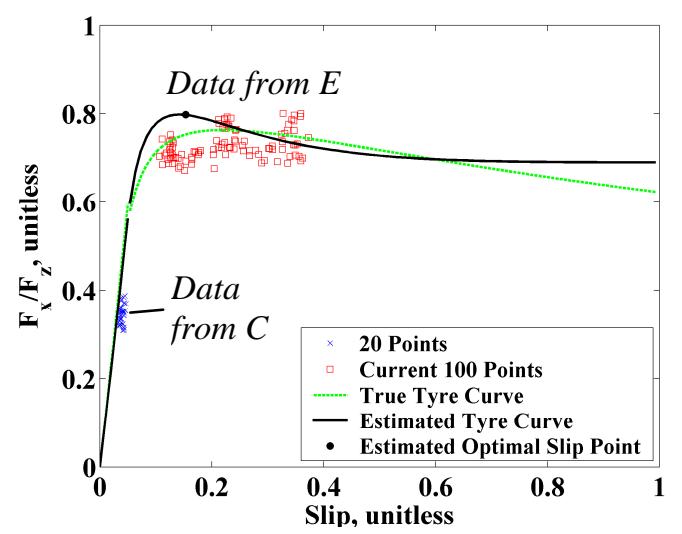

(d)

Figure 14. Simulated slip curve estimation using the nonlinear least squares algorithm on a single-wheeled model and a low friction, rough road $\left(\mu_{o}=0.2, \mathrm{IRI}=20 \mathrm{~m} / \mathrm{km}\right)$, with a change to a high friction, rough road $\left(\mu_{o}=0.9, I R I=20 \mathrm{~m} / \mathrm{km}\right)$ after $2 \mathrm{~s}$.
(a) Slip time histories
(b) Slip curve estimated at $1 \mathrm{~s}$ into the stop
(c) Slip curve estimated at $2.2 \mathrm{~s}$ into the stop
(d) Slip curve estimated at $3.2 \mathrm{~s}$ into the stop

IRI: International Road Roughness Index 


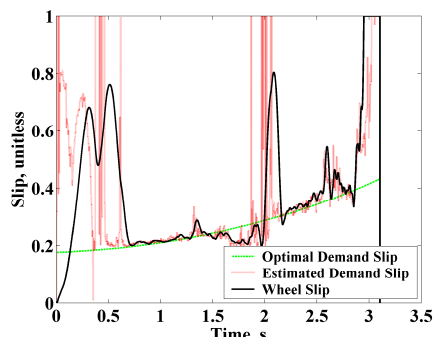

(a)

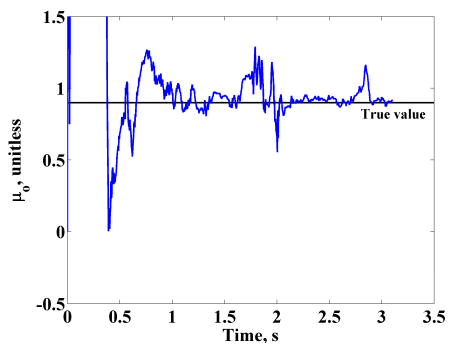

(b)

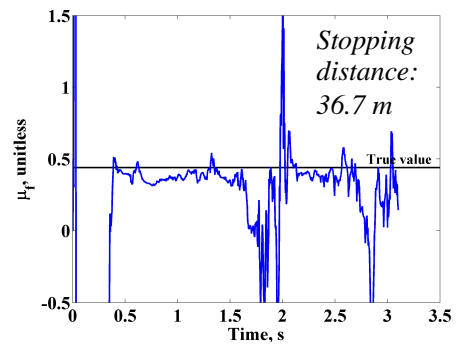

(c)

Figure 15. Simulated slip curve estimation using the recursive least squares algorithm on a single-wheeled model and a high friction, smooth road $\left(\mu_{o}=0.9, \mathrm{IRI}=0 \mathrm{~m} / \mathrm{km}\right)$

(a) Slip time histories

(b) $\mu_{o}$ estimate time history

(c) $\mu_{f}$ estimate time history

IRI: International Road Roughness Index

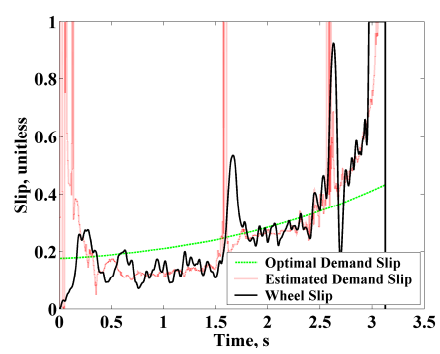

(a)

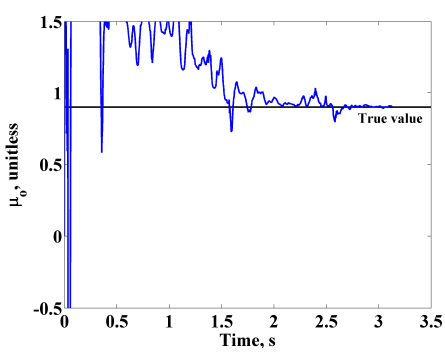

(b)

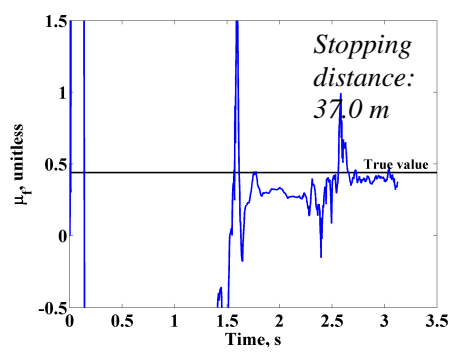

(c)

Figure 16. Simulated slip curve estimation using the recursive least squares algorithm on a single-wheeled model and a high friction, rough road $\left(\mu_{o}=0.9, \mathrm{IRI}=20 \mathrm{~m} / \mathrm{km}\right)$.

(a) Slip time histories

(b) $\mu_{o}$ estimate time history

(c) $\mu_{f}$ estimate time history

IRI: International Road Roughness Index

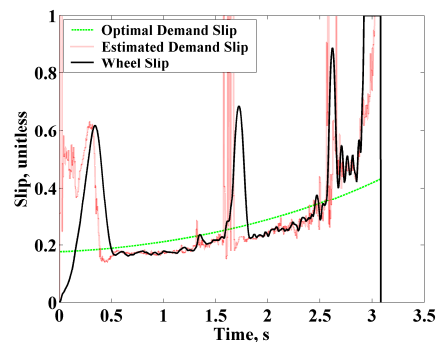

(a)

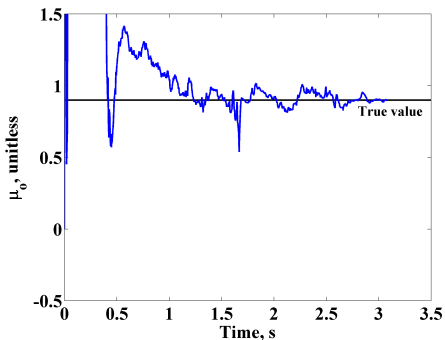

(b)

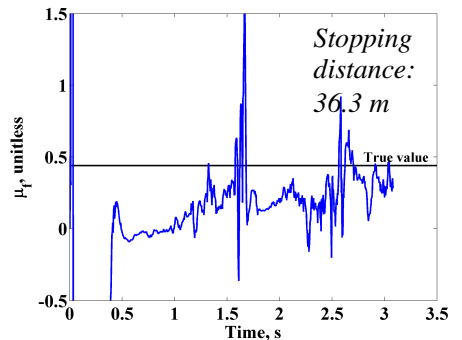

(c)

Figure 17. Simulated slip curve estimation using the recursive least squares algorithm on a single-wheeled model and a high friction, smooth road $\left(\mu_{o}=0.9, \mathrm{IRI}=0 \mathrm{~m} / \mathrm{km}\right)$ with a $30 \%$ error in the assumed values for $C_{o}$, and $V_{f}$.

(a) Slip time histories

(b) $\mu_{o}$ estimate time history 


\section{(c) $\mu_{f}$ estimate time history}

IRI: International Road Roughness Index 


\section{Notation}

$\boldsymbol{a}_{\boldsymbol{r}} \quad$ unknown parameters in the recursive least squares algorithm

$c_{t} \quad$ damping coefficient for the tyre $[\mathrm{N} \cdot \mathrm{s} / \mathrm{m}]$

$c_{S} \quad$ damping coefficient for the sprung mass $[\mathrm{N} \cdot \mathrm{s} / \mathrm{m}]$

$k \quad$ data point number [unitless]

$\boldsymbol{k}_{\boldsymbol{e}} \quad$ recursive least squares gain [unitless]

$\mathbf{k}_{\mathbf{0}} \quad$ sliding observer gain [unitless]

$k_{s} \quad$ sliding mode control gain [unitless]

$k_{t} \quad$ stiffness coefficient for the tyre [N/m]

$k_{S} \quad$ stiffness coefficient for the sprung mass $[\mathrm{N} / \mathrm{m}]$

$m_{S} \quad$ mass of the sprung body $[\mathrm{kg}]$

$m_{U} \quad$ mass of the unsprung body $[\mathrm{kg}]$

$m_{V} \quad$ vehicle mass $[\mathrm{kg}]$

$n \quad$ time step [unitless]

$q_{c} \quad$ lever ratio in the calliper [unitless]

$r_{b} \quad$ radius through which the braking force acts [m]

$r_{b r} \quad$ effective radius of the brake pads on the disc [m]

$r_{r} \quad$ rolling radius of the wheel [m]

$s_{s} \quad$ sliding mode control switching surface [unitless]

$u \quad$ control system input

$v_{x} \quad$ longitudinal velocity $[\mathrm{m} / \mathrm{s}]$

$\boldsymbol{w}_{\boldsymbol{m}} \quad$ random noise in the measurements

$\boldsymbol{w}_{\boldsymbol{s}} \quad$ random noise in the states

x control system states

$\boldsymbol{y}$ control system outputs

$z_{r} \quad$ vertical position of the road [m]

$z_{S} \quad$ vertical position of the sprung mass [m]

$z_{U} \quad$ vertical position of the unsprung mass [m]

A system matrix of the control system

$A_{c} \quad$ effective force-area of the chamber diaphragm $\left[\mathrm{m}^{2}\right]$

B control system input matrix

C control system output matrix

$C_{1} \quad$ constant coefficient [unitless]

$C_{2} \quad$ constant coefficient [N]

$C_{o} \quad$ longitudinal tyre stiffness [N]

$F_{x} \quad$ longitudinal (braking) force [N]

$F_{z} \quad$ vertical load on the tyre $[\mathrm{N}]$

$G \quad$ brake gain $[\mathrm{N} \cdot \mathrm{m} / \mathrm{Pa}]$

$J \quad$ least squares objective function

$J_{w} \quad$ moment of inertia of the wheel $\left[\mathrm{kg} \bullet \mathrm{m}^{2}\right]$

L Luenberger observer gain

$L_{x} \quad$ fraction of the contact patch that is not sliding [unitless]

$N \quad$ total number of data points [unitless]

$P_{c} \quad$ pressure in the brake chamber $[\mathrm{Pa}]$

P covariance matrix

$T_{B} \quad$ braking torque at the wheel $[\mathrm{N} \cdot \mathrm{m}]$

$V_{f} \quad$ coefficient describing the shape at the peak of the slip curve [unitless]

$\delta_{s} \quad$ parameter describing width of the switching surface boundary layer [unitless] 
$\boldsymbol{\theta}_{\boldsymbol{r}}$ observation matrix in the recursive least squares algorithm

$\lambda \quad$ wheel slip [unitless]

$\mu \quad$ coefficient of friction between the tyre and the road [unitless]

$\mu_{b r} \quad$ coefficient of friction between the brake pads and the disc [unitless]

$\mu_{f} \quad$ coefficient of dynamic (sliding) friction [unitless]

$\mu_{o} \quad$ coefficient of peak friction [unitless]

$\omega_{w}$ rotational velocity of the wheel $[\mathrm{rad} / \mathrm{s}]$

$\phi \quad$ forgetting factor for the recursive least squares algorithm [unitless]

$\Phi_{s} \quad$ proportional gain in the sliding mode controller [unitless] 